\title{
Elevated extracellular calcium ions promote proliferation and migration of mesenchymal stem cells via increasing osteopontin expression
}

\author{
Mi Nam Lee ${ }^{1,2}$, Hee-Su Hwang ${ }^{1,2}$, Sin-Hye Oh 1,2, Amir Roshanzadeh33, Jung-Woo Kim ${ }^{1,2}$, Ju Han Song ${ }^{1,2}$, \\ Eung-Sam Kim ${ }^{4}$ and Jeong-Tae Koh ${ }^{1,2}$
}

\begin{abstract}
Supplementation of mesenchymal stem cells (MSCs) at sites of bone resorption is required for bone homeostasis because of the non-proliferation and short lifespan properties of the osteoblasts. Calcium ions $\left(\mathrm{Ca}^{2+}\right)$ are released from the bone surfaces during osteoclast-mediated bone resorption. However, how elevated extracellular $\mathrm{Ca}^{2+}$

concentrations would alter MSCs behavior in the proximal sites of bone resorption is largely unknown. In this study, we investigated the effect of extracellular $\mathrm{Ca}^{2+}$ on MSCs phenotype depending on $\mathrm{Ca}^{2+}$ concentrations. We found that the elevated extracellular $\mathrm{Ca}^{2+}$ promoted cell proliferation and matrix mineralization of MSCs. In addition, MSCs induced the expression and secretion of osteopontin (OPN), which enhanced MSCs migration under the elevated extracellular $\mathrm{Ca}^{2+}$ conditions. We developed in vitro osteoclast-mediated bone resorption conditions using mouse calvaria bone slices and demonstrated $\mathrm{Ca}^{2+}$ is released from bone resorption surfaces. We also showed that the MSCs phenotype, including cell proliferation and migration, changed when the cells were treated with a bone resorptionconditioned medium. These findings suggest that the dynamic changes in $\mathrm{Ca}^{2+}$ concentrations in the microenvironments of bone remodeling surfaces modulate MSCs phenotype and thereby contribute to bone regeneration.
\end{abstract}

\section{Introduction}

Bone is remodeled throughout adult life not only to regulate mineral homeostasis but also to maintain the integrity and biomechanical stability of the skeleton ${ }^{1}$. Bone remodeling is accomplished through tightly regulated and continuous cycles of osteoclastic and osteoblastic activity in the bone matrix ${ }^{2}$. This process requires osteoblast mobilization to the sites of bone reconstruction. However, because osteoblasts are non-proliferative

Correspondence: Jeong-Tae Koh (jtkoh@chonnam.ac.kr)

${ }^{1}$ Research Center for Biomineralization Disorders, School of Dentistry, Chonnam National University, Gwangju, Republic of Korea

2Department of Pharmacology and Dental Therapeutics, School of Dentistry, Chonnam National University, Gwangju, Republic of Korea

Full list of author information is available at the end of the article. and have a short lifespan, the replenishment of osteoblasts from MSCs is required for continuous bone formation ${ }^{3}$. Indeed, defects in MSCs recruitment are associated with several skeletal pathologies including osteoporosis ${ }^{4,5}$. Therefore, stimulation of MSCs recruitment to sites of bone formation represents a promising strategy for bone regeneration.

During osteoclast-mediated bone resorption, multiple factors released from bone matrix locally are known to create an osteogenic microenvironment that promotes MSCs recruitment and osteoblast differentiation resulting in new bone formation. The osteoclastic bone resorptive sites contain several soluble factors, including transforming growth factor $\beta 1$ (TGF $\beta 1$ ) and insulin growth factor 1 , which act as a chemoattractant to 
induce cell migration in vitro ${ }^{6-8}$. TGF $\beta 1$ is one of the most abundant cytokines in the bone matrix, which is released and activated during osteoclast-mediated bone resorption ${ }^{6,9-11}$. Previously, using an in vivo mouse tibial fracture model, TGF $\beta 1$ was suggested to be critical in the recruitment of MSCs to bone remodeling sites by mediating Smad signaling pathway ${ }^{12}$. Other growth factors and cytokines are also reported to regulate MSCs migration in vitro so far ${ }^{13}$.

Calcium ions $\left(\mathrm{Ca}^{2+}\right)$ are released from bone matrix during osteoclast-mediated bone resorption, although the exact concentration of extracellular $\mathrm{Ca}^{2+}$ during bone remodeling in vivo is still unknown. The resorptive action of osteoclasts results in a local increase of extracellular $\mathrm{Ca}^{2+}$ concentration as high as $40 \mathrm{mM}$ in vitro ${ }^{14}$. Another study showed that the extracellular $\mathrm{Ca}^{2+}$ concentrations between the basal aspect of cells and substrate of damage zones of bone can increase to $10 \mathrm{mM}$ within sec, suggesting fluctuation within the range of $9-180 \mathrm{mM}$ at the sites of damage in vivo ${ }^{15}$. Indeed, the effect of elevated extracellular $\mathrm{Ca}^{2+}$ on osteoblasts-mediated bone formation has been evaluated ${ }^{16-19}$. Many studies have focused on the effect of extracellular $\mathrm{Ca}^{2+}$ on committed osteoblasts, while a few recent reports showed that $\mathrm{Ca}^{2+}$ concentration also influenced MSCs phenotypes, including cell proliferation and differentiation ${ }^{20-24}$. However, the direct effect of $\mathrm{Ca}^{2+}$ released from bone resorption surfaces on MSCs function has not been evaluated, and moreover, the role of extracellular $\mathrm{Ca}^{2+}$ in MSCs migration is largely unknown.

In this study, we investigated the role of elevated extracellular $\mathrm{Ca}^{2+}$ in MSCs phenotype alterations and the effects of $\mathrm{Ca}^{2+}$ released from bone resorption surface on MSCs behavior. We suggest that the elevated extracellular $\mathrm{Ca}^{2+}$ represents a critical factor in the expansion of MSCs population in bone remodeling sites by activating cell proliferation and migration.

\section{Materials and methods \\ Reagents}

We used the recombinant mouse OPN, TGF $\beta 1$, and FGF2 supplied by R\&D Systems (Minneapolis, MN, USA). Recombinant human bone morphogenetic protein 2 (BMP2) was purchased from CowellMedi (Busan, South Korea). Quantikine Mouse/Rat osteopontin, Mouse/Rat/Porcine/Canine TGF $\beta 1$, and Mouse/Rat FGF basic ELISA kits were obtained from R\&D Systems. Cell Counting Kit-8 (CCK-8) assay kit was supplied by Dojindo Laboratories (Kumamoto, Japan), and BrdU incorporation assay kit was ordered through Cell Signaling Technology (Danvers, MA, USA). The molecular biology-grade reagents were purchased from Sigma-Aldrich (St. Louis, MO, USA) unless stated otherwise.

\section{Cell culture}

C3H10T1/2 cells obtained from the American Type Culture Collection (ATCC, Manassas, VA, USA) were maintained in Dulbecco's modified Eagle's medium (DMEM) (Gibco/Thermo Fisher Scientific, Waltham, MA, USA) containing $10 \%$ fetal bovine serum (FBS) (Gibco/Thermo Fisher Scientific), supplemented with 100 $\mathrm{U} / \mathrm{mL}$ of penicillin and $100 \mu \mathrm{g} / \mathrm{mL}$ of streptomycin (Invitrogen/Thermo Fisher Scientific). Mouse bone marrow MSCs (BM-MSCs) were isolated from the femurs of 6-8-week-old male C57BL/6 mice as previously described $^{25}$. BM-MSCs were cultured in $\alpha$-minimal essential medium ( $\alpha$-MEM) (Gibco/Thermo Fisher Scientific) supplemented with $10 \% \mathrm{FBS}, 100 \mathrm{U} / \mathrm{mL}$ of penicillin, and $100 \mu \mathrm{g} / \mathrm{mL}$ of streptomycin. We used BM-MSCs at passage 3 for further experimentation.

\section{Cell proliferation assay}

Cells were incubated with $2 \% \mathrm{FBS} /$ medium containing the indicated amount of $\mathrm{CaCl}_{2}$ for $48 \mathrm{~h}$. The following media containing increasing extracellular $\mathrm{Ca}^{2+}$ concentrations were used for this study: $1.8 \mathrm{mM} \mathrm{Ca}^{2+}$ (standard culture medium, $\mathrm{SM}$, contains $1.8 \mathrm{mM} \mathrm{CaCl}_{2}$ ), $4 \mathrm{mM} \mathrm{Ca}^{2+}\left(\mathrm{SM}+2.2 \mathrm{mM} \mathrm{CaCl}_{2}\right), 6 \mathrm{mM} \mathrm{Ca}^{2+}(\mathrm{SM}+4.2$ $\mathrm{mM} \mathrm{CaCl} 2), 8 \mathrm{mM} \mathrm{Ca}^{2+}\left(\mathrm{SM}+6.2 \mathrm{mM} \mathrm{CaCl}_{2}\right), 10 \mathrm{mM}$ $\mathrm{Ca}^{2+}(\mathrm{SM}+8.2 \mathrm{mM} \mathrm{CaCl})$, and $20 \mathrm{mM} \mathrm{Ca}^{2+}(\mathrm{SM}+$ $18.2 \mathrm{mM} \mathrm{CaCl}_{2}$ ). For OPN neutralizing antibody assays, the indicated concentration of OPN neutralizing antibody (R\&D Systems) was added to elevated extracellular $\mathrm{Ca}^{2+}$ medium. Cell proliferation was determined using a CCK-8 assay or a BrdU incorporation assay as previously described $^{26}$. Relative proliferation rates were determined by normalizing the absorbance value of the experimental groups to that of control group. Values for the relative proliferation rates represented as the mean \pm SEM of triplicate reactions in one representative experiment.

\section{Real-time PCR}

Total RNA was isolated from cells using TRIzol reagent (Invitrogen/Thermo Fisher Scientific) and $1 \mu \mathrm{g}$ of total RNA was reverse transcribed using a reverse transcription system (200 U of M-MLV, $0.5 \mathrm{mM}$ of dNTP, $40 \mathrm{U}$ of RNAsin, and $200 \mathrm{ng}$ of random primer) (Promega, Madison, WI, USA), according to the manufacturer's protocol. We used the StepOnePlus Real-Time PCR System (ABI, Abilene, TX, USA) for quantitative real-time PCR. PCR was carried out in a final volume of $20 \mu \mathrm{L}$ using 10 pmol of each primer (listed below), $5 \mu \mathrm{L}$ of cDNA (5 $\mathrm{ng} / \mu \mathrm{L})$, and $10 \mu \mathrm{L}$ of Power SYBR Green PCR Master Mix (ABI, Valencia, CA, USA). PCR was performed with a 5 min pre-incubation period at $95^{\circ} \mathrm{C}$, followed by 40 cycles of $30 \mathrm{~s}$ each at $95^{\circ} \mathrm{C}, 30 \mathrm{~s}$ at $56^{\circ} \mathrm{C}$, and $30 \mathrm{~s}$ at $72{ }^{\circ} \mathrm{C}$. We performed all reactions in triplicate, and normalized the expression levels of all mRNAs to the expression level of 
endogenous $\beta$-actin. The relative target gene expression was quantified using the comparative $\mathrm{Ct}$ method. Values for the relative expression of the indicated genes represent the mean \pm SEM of triplicate reactions in one representative experiment. The sequences of the primers used were as follows: for $\beta$-actin, $5^{\prime}$-GCCATCTCCTGCTCGA AGTC-3' and 5'-ACCCACACTGTGCCCATCTA-3'; for FGF2, $5^{\prime}$-CACCAGGCCACTTCAAGGA- ${ }^{\prime}$ and $5^{\prime}$-GAT GGATGCGCAGGAAGAA-3'; for TGF $\beta 1$, $5^{\prime}$-AACAATT CCTGGCGTTACCTT-3' and 5'-ATTCCGTCTCCTTG GTTCAG-3'; for OPN, 5'-GATTTGCTTTTGCCTGTT TGG- ${ }^{\prime}$ ' and 5' $^{\prime}$-TGAGCTGCCAGAATCAGTCACT-3'

\section{Western blotting analysis}

Total protein was extracted from the cells with lysis buffer (Cell Signaling Technology) and the protein concentration was measured using the $\mathrm{BCA}$ protein assay reagent (Bio-Rad Laboratories, Hercules, CA, USA). A protein concentration of 20-30 $\mu$ g was used to analyze the protein expression level using primary antibodies against OPN (Santa Cruz Biotechnology, Dallas, TX, USA), cyclin D1 (Cell Signaling Technology), c-Jun (Cell Signaling Technology), and $\beta$-actin (Santa Cruz Biotechnology, Dallas, TX, USA). After incubation with secondary horseradish peroxidase-conjugated anti-mouse or antirabbit antibodies (Thermo Fisher Scientific), we visualized the signals using an enhanced chemiluminescence reagent (ECL; Millipore, Billerica, MA, USA) in a LAS-4000 lumino-image analyzer system (Fujifilm, Tokyo, Japan), followed by semiquantitative evaluation of the bands using densitometry (Multi Gauge V3.0, Fujifilm). The blotting results are representative of three independent experiments.

\section{Enzyme-linked immunosorbent assay (ELISA)}

Quantitative analysis of OPN, TGF $\beta 1$, and FGF2 in conditioned medium was performed by ELISA according to the manufacturer's instructions. Active TGF $\beta 1$ was not detected in any conditioned medium before the activation of the latent TGF $\beta 1$ by sequential treatment with $1 \mathrm{~N} \mathrm{HCl}$ and $1.2 \mathrm{~N} \mathrm{NaOH} / 0.5 \mathrm{M}$ HEPES. Absorbance was measured by a plate reader (Thermo Fisher Scientific). Values for the proteins levels were expressed as the mean \pm SEM of a duplicate reaction of one representative experiment.

\section{Osteoblast differentiation}

Cells were seeded on 48-well culture plates at $5 \times 10^{4}$ cells/well. After $24 \mathrm{~h}$, cells were changed with OM $(50 \mu \mathrm{g} /$ $\mathrm{mL}$ of ascorbic acid, $5 \mathrm{mM}$ of $\beta$-glycerophosphate, and $100 \mathrm{ng} / \mathrm{mL}$ of BMP2) containing the indicated amount of extracellular $\mathrm{Ca}^{2+}$. The medium was replaced every 3 days for 16 days. To evaluate matrix mineralization, cells were fixed with $70 \%$ cold ethanol and treated with $40 \mathrm{mM}$ of alizarin red solution $(\mathrm{pH} 4.2)$ for $30 \mathrm{~min}$. The stained culture plates were scanned with an Epson Perfection V700 (Epson Korea, Seoul, South Korea), and the stained cells were observed via optical microscopy (magnification: 50x, Leica Microsystems, Wetzlar, Germany). The alizarin red stain was extracted with $10 \%(\mathrm{w} / \mathrm{v})$ cetylpyridinium chloride in $10 \mathrm{mM}$ of sodium phosphate $(\mathrm{pH} 7.0)$ for 15 min and absorbance were measured by a spectrophotometry (Thermo Fisher Scientific).

\section{Cell migration assay}

Cell migration assay was evaluated using a 24-well Transwell chamber $(8 \mu \mathrm{m}$ pores, SPL, South Korea). Briefly, 2\% FBS culture media containing the indicated amount of extracellular $\mathrm{Ca}^{2+}$ were loaded in the lower chambers. C3H10T1/2 or BM-MSCs $\left(2 \times 10^{4}\right.$ cells/well $)$ were suspended in serum-free standard medium, and added to the upper chamber. To neutralize secreted OPN, the indicated culture medium was pre-incubated with an OPN neutralizing antibody (R\&D Systems) for $1 \mathrm{~h}$ and used as the lower chamber medium. After incubation for the indicated durations, cells migrating to the opposite side of the membrane were fixed with $4 \%$ paraformaldehyde and stained with $0.05 \%$ crystal violet in $2 \%$ ethanol. The migrated cells were counted at least in five fields using a light microscope. Data represent the number of total migrated cells per field of view (FV, x50 magnification) or as fold increase related to that of control.

\section{Preparation of bone resorption-conditioned medium (BRCM)}

To prepare the osteoclastic BRCM, osteoclast differentiation was induced from bone marrow-derived macrophages (BMMs) on the surface of mouse calvarial bone slices. To prepare bone slices, 6-8-week-old male C57BL/ 6 mice were sacrificed, and a 5-mm-diameter calvarial bone was cut off from each side of the calvariae using a trephine bur (Fine Science Tools, Foster City, CA). Any adherent tissue and periosteum were cleaned off with a scalpel. Bone slices were washed with PBS containing $0.1 \%$ Triton X-100 several times. After washing with PBS, bone slices were stored in $70 \%$ ethanol under frozen condition until use. BMMs were isolated from femurs of 6-week-old C57BL/6 mice and cultured in $\alpha$-MEM containing $10 \% \mathrm{FBS}$ and $30 \mathrm{ng} / \mathrm{mL}$ of recombinant M-CSF (R\&D Systems) for 3 days. Cells were collected and $5 \times 10^{4}$ cells were plated on the prepared calvarial bone slice. To induce osteoclast differentiation, cells were cultured in the presence of RANKL (100 ng/ml, R\&D Systems) and MCSF $(30 \mathrm{ng} / \mathrm{ml})$. The precursor cell-conditioned medium (PCM) was prepared by culturing the cells in the presence of M-CSF $(30 \mathrm{ng} / \mathrm{ml})$. The culture medium without BMMs was used as a negative control (CCM). The conditioned medium was collected and was replaced with fresh medium every other day for 16 days. We selected 4- 
day interval samples from each group and used these to measure extracellular $\mathrm{Ca}^{2+}$ concentrations or to perform further experiments. The cultured cells were stained for tartrate-resistant acid phosphatase (TRAP) activity (TRAP staining kit, Sigma-Aldrich). To confirm the topography of excavations made by osteoclasts in calvarial bone slices, the bone surface was analyzed using scanning electron microscopy (SEM) (Hitachi SU-70, Tokyo, Japan).

\section{Measurement of extracellular calcium concentration}

The quantity of calcium ions released from the calvarial bone slices was determined using a calcium colorimetric assay kit (BioVision, Milpitas, CA, USA). The conditioned medium prepared as described above was analyzed according to the manufacturer's instructions. Values represent the mean \pm SEM of a triplicate reaction of one representative experiment.

\section{Statistical analyses}

All experiments were repeated at least three times independently. Data were analyzed with Prism5 (GraphPad, La Jolla, CA, USA) for statistical significance and expressed as mean \pm SEM. Statistical analysis was performed by one-way ANOVA followed by Tukey post-hoc test unless stated otherwise.

\section{Results}

Extracellular $\mathrm{Ca}^{2+}$ is an important factor for determining MSCs phenotype

$\mathrm{Ca}^{2+}$ concentrations reach as high as $40 \mathrm{mM}$ at the bone resorption site ${ }^{14}$. Therefore, cells were treated with culture medium containing diverse $\mathrm{Ca}^{2+}$ concentrations ranging from $1.8 \mathrm{mM}$ up to $40 \mathrm{mM}$. However, due to cellular toxicity above $30 \mathrm{mM}$, we used $20 \mathrm{mM}$ as the highest extracellular $\mathrm{Ca}^{2+}$ concentration in this study. Proliferation of both C3H10T1/2 cells and primary BMMSCs were promoted at the same range of extracellular $\mathrm{Ca}^{2+}$ concentration and this effect reached a maximum of $6 \mathrm{mM}$ concentration and thereafter gradually declined (Fig. 1a). Treatment with $6 \mathrm{mM} \mathrm{Mg}^{2+}$ or co-treatment with $8 \mathrm{mM} \mathrm{Ca}^{2+}$ and $8 \mathrm{mM}$ EGTA $\left(\mathrm{Ca}^{2+}\right.$ chelator) had no effect (Figs. 1a, b), suggesting the specific role of extracellular $\mathrm{Ca}^{2+}$ on MSCs proliferation.

We examined whether elevated extracellular $\mathrm{Ca}^{2+}$ affects the migration of MSCs in the Transwell assay. We found an increase in migrated cell numbers under elevated extracellular $\mathrm{Ca}^{2+}$ concentrations in both C3H10T1/2 cells and BM-MSCs (Figs. 1c, d, bottom left). Since elevated extracellular $\mathrm{Ca}^{2+}$ promotes cell proliferation (Fig. 1a), we further calculated the migration of cells by correcting the effect of proliferation on the number of migrated cells during the $24 \mathrm{~h}$ treatment; The migration capacity (chemotactic index) increased two-fold in C3H10T1/2 cells and eight-fold in BM-MSCs (Figs. 1c, d, bottom right). There was little effect of high concentration of extracellular $\mathrm{Mg}^{2+}$ and $\mathrm{Ca}^{2+}$ on attachment and spreading of MSCs (Supplementary Figure 1).

There are controversial reports on the effect of elevated extracellular $\mathrm{Ca}^{2+}$ on osteogenic differentiation and matrix mineralization ${ }^{21,23,27}$. We found that matrix mineralization was significantly enhanced by the elevated extracellular $\mathrm{Ca}^{2+}$. Interestingly, this effect was sustained up to $20 \mathrm{mM} \mathrm{Ca}^{2+}$ in growth medium conditions, whereas decreased after $6 \mathrm{mM} \mathrm{Ca}^{2+}$ concentration under osteogenic induction conditions (OM) (Supplementary Figure 2a). Extracellular $\mathrm{Mg}^{2+}$ had little effect on matrix mineralization (Supplementary Figure 2a). From these results, we suggest that elevated extracellular $\mathrm{Ca}^{2+}$ potentiates matrix mineralization even in the absence of osteogenic factors, and this effect was limited to the specific range of $\mathrm{Ca}^{2+}$ concentrations under osteogenic induction conditions.

\section{Extracellular $\mathrm{Ca}^{2+}$ concentration induces the expression of FGF2, TGF $\beta 1$, and OPN in MSCs}

To investigate potential factors underlying the potent role of extracellular $\mathrm{Ca}^{2+}$ in MSCs, we examined the expression levels of several growth factors and transcription factors that are known to play major roles in MSCs function. Cells were treated with either 6 or $8 \mathrm{mM} \mathrm{Ca}^{2+}$, the optimal concentration to alter MSC phenotype (Fig. 1a), in order to mimic the condition with elevated extracellular $\mathrm{Ca}^{2+}$. We found a significant increase in FGF2, TGF $\beta 1$, and OPN expression under elevated extracellular $\mathrm{Ca}^{2+}$ (Supplementary Figure 3). FGF2 expression increased after $2 \mathrm{~h}$ of treatment, and no longer responded at $72 \mathrm{~h}$ (Figs. 2a-c). TGF $\beta 1$ expression induced after $24 \mathrm{~h}$ of treatment was sustained up to $48 \mathrm{~h}$ (Fig. 2a, b), when the expression also showed a $\mathrm{Ca}^{2+}$ concentration dependency (Fig. 2d). No TGF $\beta 1$ induction occurred after $72 \mathrm{~h}$ post-treatment (Fig. 2c). The OPN expression induced at $12 \mathrm{~h}$ increased dramatically up to $72 \mathrm{~h}$ after treatment (Figs. 2a-c). OPN expression reached a maximum at $10 \mathrm{mM}$ concentration and subsequently declined (Fig. 2d). The effect of extracellular $\mathrm{Ca}^{2+}$ on FGF2, TGF $\beta 1$, and OPN gene expression was also observed in BM-MSCs (Fig. 2e). Based on these results, we suggest an intrinsic regulation of the expression of these three factors in response to the changes in extracellular $\mathrm{Ca}^{2+}$ concentration, although their gene expression patterns vary slightly.

\section{MSCs secrete OPN under the elevated extracellular $\mathrm{Ca}^{2+}$ conditions}

Because FGF2, TGF $\beta 1$, and OPN are secretory factors, we investigated the increase in their levels in the conditioned medium from cells stimulated by elevated extracellular $\mathrm{Ca}^{2+}$. Consistent with data from Fig. 2, a high 


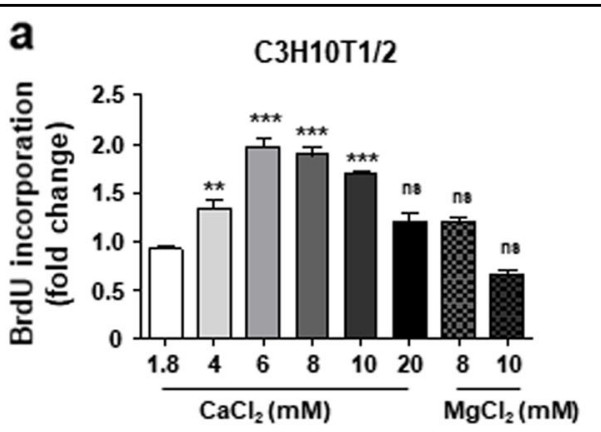

BM-MSCs

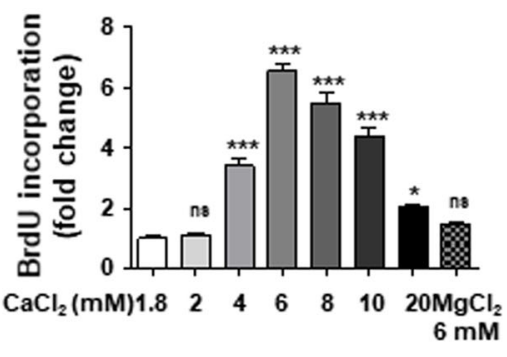

b
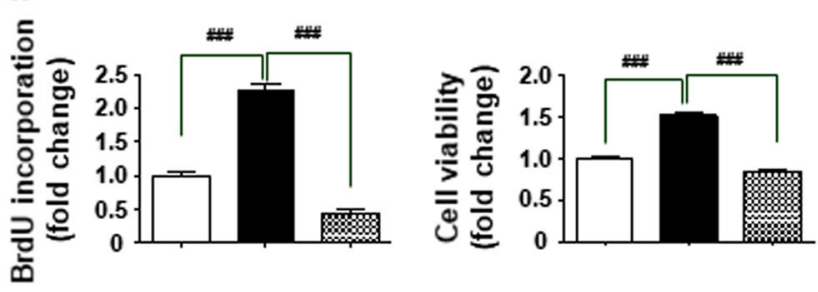

$\square \mathrm{CaCl}_{2} 1.8 \mathrm{mM}$

- $\mathrm{CaCl}_{2} 8 \mathrm{mM}$

Q $\mathrm{CaCl}_{2} 8 \mathrm{mM}+\mathrm{EGTA} 8 \mathrm{mM}$

C

$\mathrm{CaCl}_{2}(\mathrm{mM})$

\begin{tabular}{|c|c|c|c|c|c|}
\hline 1.8 & 4 & 6 & 8 & 10 & 20 \\
\hline & & & 8 & & 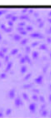 \\
\hline
\end{tabular}
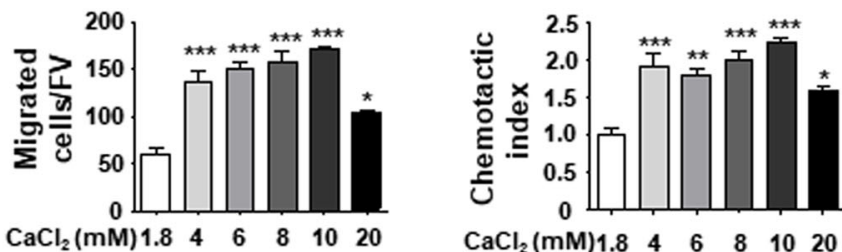

d

$2 \%$ FBS
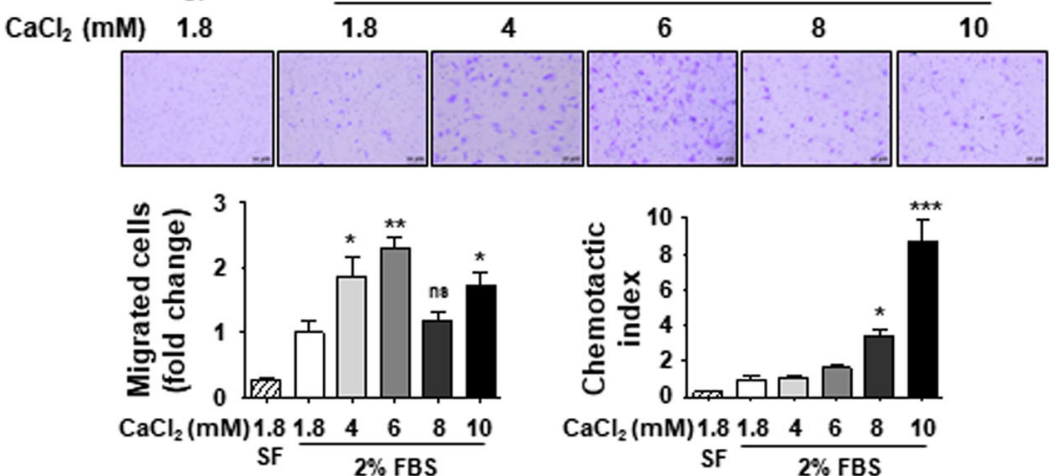

Fig. 1 Effect of extracellular $\mathrm{Ca}^{2+}$ on MSCs behavior. $\mathbf{a}, \mathbf{b}$ Extracellular $\mathrm{Ca}^{2+}$ promotes cell proliferation in a concentration-dependent manner. Cells were cultured in $2 \% \mathrm{FBS}$-containing medium for $48 \mathrm{~h}$ with the indicated amounts of either $\mathrm{CaCl}_{2}$ or $\mathrm{MgCl}_{2}$. EGTA was used as a Ca ${ }^{2+}$ chelator. Cell proliferation was measured by the BrdU incorporation assay and cell viability was determined by CCK-8 assay. $\mathbf{c}$, d Extracellular Ca ${ }^{2+}$ promotes cell migration in a concentration-dependent manner. C3H10T1/2 cells (c) and BM-MSCs (d) were used in Transwell assay with the indicated amounts of $\mathrm{CaCl}_{2}$-containing medium in the lower chamber. Cells that migrated to the lower side of the well for $24 \mathrm{~h}$ were fixed and stained. The number of migrated cells per field of view (FV, x50 magnification) is indicated (bottom left in c). The number of migrated cells was expressed as the fold increases relative to control (bottom left in $\mathbf{d}$ ). The migration capacity of cells was expressed as the chemotatic index by correcting the effect of $\mathrm{Ca}^{2+}$ on the proliferation of migrated cells during the $24 \mathrm{~h}$ treatment (chemotatic index = migrating cell number/fold change of proliferating cells, bottom right). SF (serum-free medium), negative control. ${ }^{*} p<0.05 ;{ }^{* *} p<0.01$; ${ }^{* * *} p<0.001$ vs. first bar, ${ }^{\#} p<0.05 ;{ }^{\# \#} p<0.01$; ${ }^{\# \#} p<0.001$ vs. indicated group 

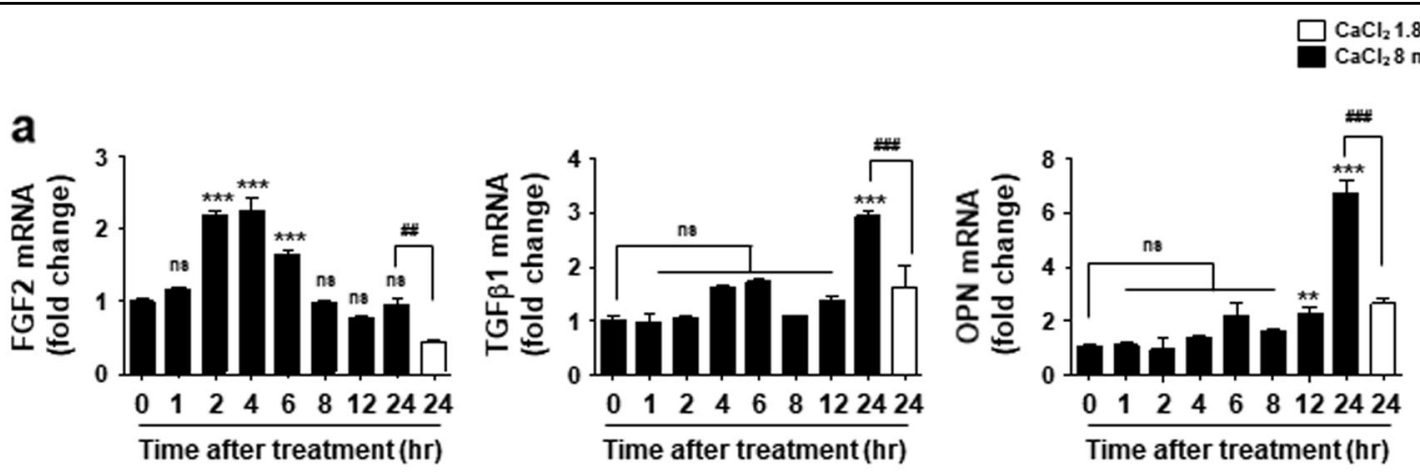

b
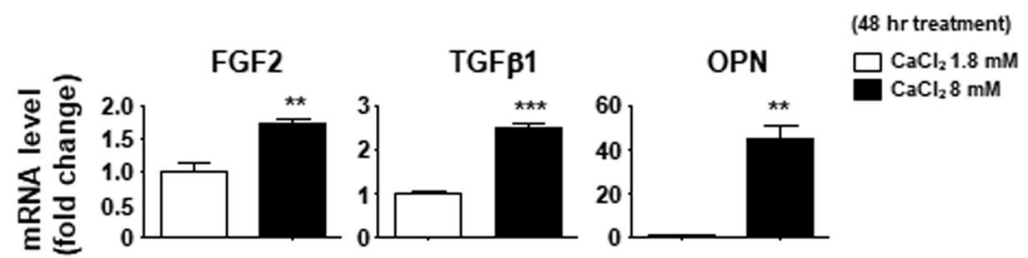

C

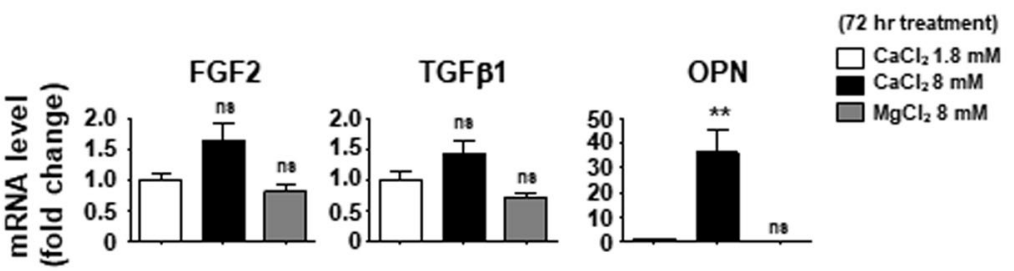

d
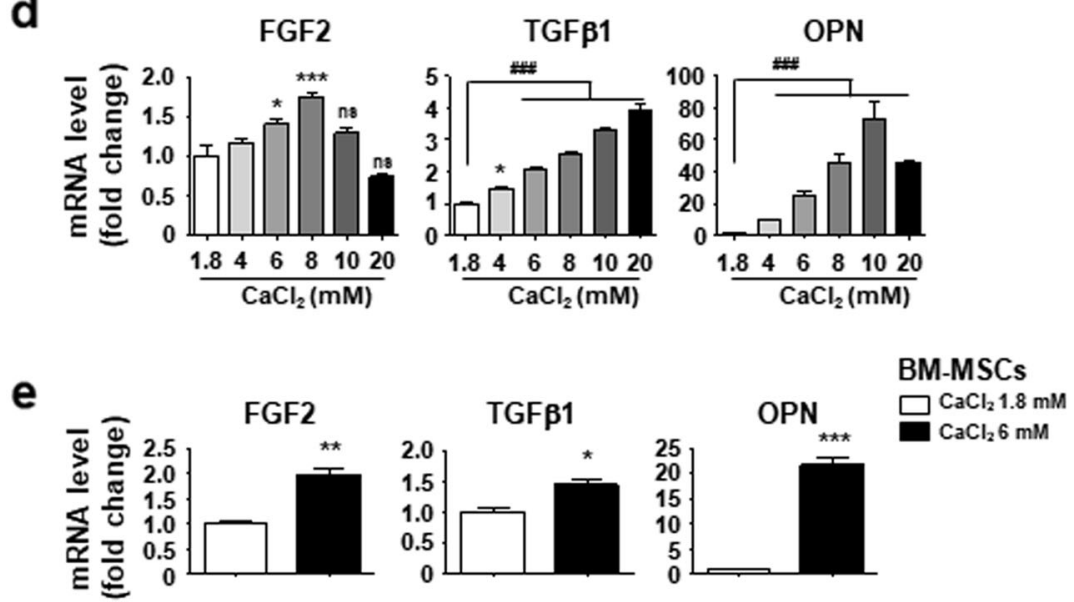

Fig. 2 Elevated extracellular $\mathrm{Ca}^{2+}$ induces the expression of FGF2, TGF $\beta 1$ and OPN in a time and dose-dependent manner. a-c Time courses of FGF2, TGF $\beta 1$, and OPN expression after exposure to $8 \mathrm{mM} \mathrm{Ca}^{2+}$. C3H10T1/2 cells were incubated with standard medium $\left(1.8 \mathrm{mM} \mathrm{Ca}{ }^{2+}\right)$ or $8 \mathrm{mM}$ $\mathrm{Ca}^{2+}$ medium for the indicated time $(\mathbf{a}) ; 48 \mathrm{~h}(\mathbf{b}) ; 72 \mathrm{~h}(\mathbf{c}) . \mathbf{d} \mathrm{C} 3 \mathrm{H} 10 \mathrm{~T} 1 / 2$ cells were treated with a medium containing the indicated concentration of $\mathrm{Ca}^{2+}$ for $48 \mathrm{~h}$. e BM-MSCs were incubated with standard medium or $6 \mathrm{mM} \mathrm{Ca}^{2+}$ medium for $48 \mathrm{~h}$. a-e Cells were harvested and subjected to realtime RT-PCR to analyze expression levels of FGF2, TGF $\beta 1$, and OPN. Values for the relative expression of the indicated genes are expressed as the mean \pm SEM of triplicate reactions in one representative experiment. $\mathbf{a}, \mathbf{c}$, and $\mathbf{d}$ Statistical analysis was performed by ANOVA followed by the Tukey post hoc test. ${ }^{* *} p<0.01 ;{ }^{* *} p<0.001$ vs. first bar. ${ }^{\# \#} p<0.01 ;{ }^{\# \#} p<0.001$ vs. indicated group. $\mathbf{b}$ and $\mathbf{e}$ Statistical analysis was performed by Student's $t-$ test, ${ }^{*} p<0.05 ;{ }^{* *} p<0.01 ;{ }^{* * *} p<0.001$ vs. first bar

level of OPN was detected in the conditioned medium at $48 \mathrm{~h}$ treatment (Fig. 3a). While active TGF $\beta 1$ was detected in all conditioned media, there was no further increase in the elevated extracellular $\mathrm{Ca}^{2+}$-conditioned medium
(Fig. 3a). We could not evaluate the secretion of FGF2 by the stimulated MSCs, because FGF2 was rarely detected in the conditioned media (Fig. 3a). We presumed that the amount of FGF2 in the conditioned media was less 
a

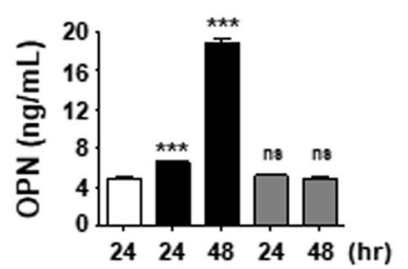

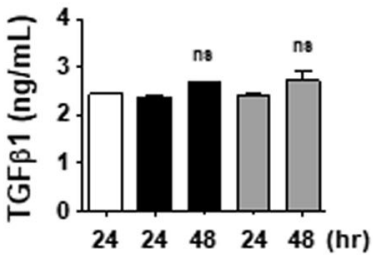

$24 \quad 24 \quad 48 \quad 24 \quad 48(\mathrm{hr})$

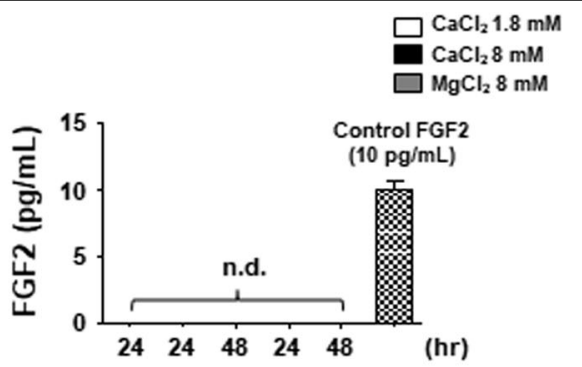

b

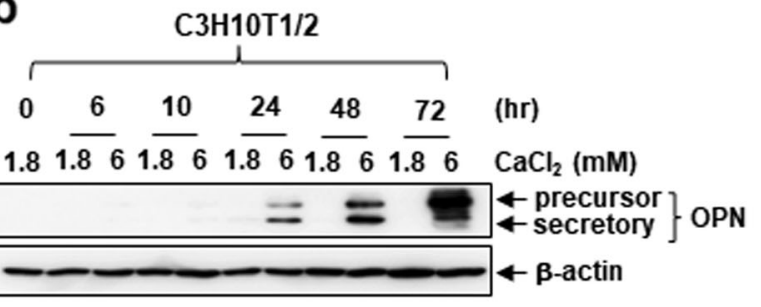

C

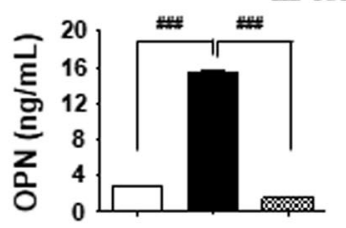

d

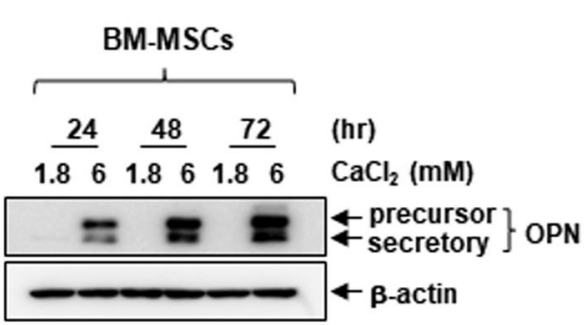

e
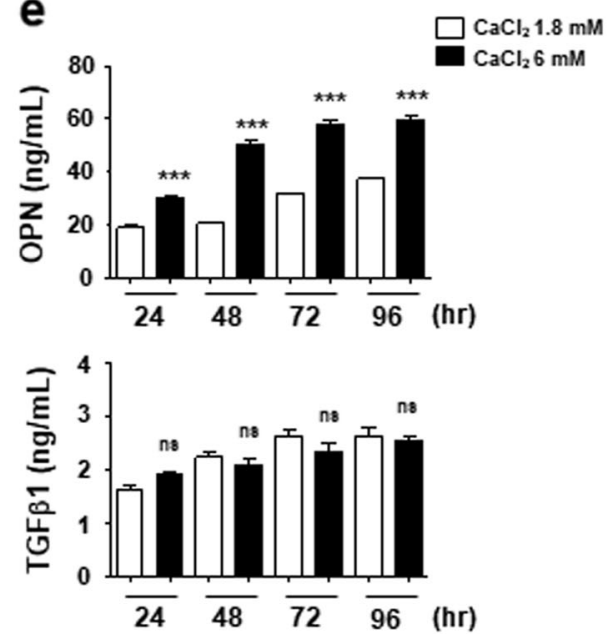

Fig. 3 Extracellular OPN is increased by MSCs under elevated extracellular $\mathrm{Ca}^{2+}$ conditions. a Measurement of extracellular OPN, TGF $\beta 1$, and FGF2 in the indicated conditioned medium. Conditioned medium was harvested from different cultures of C3H10T1/2 cells as indicated and used to ELISA as described in the Materials and methods section. $\mathbf{b}$ and $\mathbf{d}$ Time course of effect of elevated extracellular $\mathrm{Ca}^{2+}$ on OPN protein levels. C3H10T1/2 cells (b) and BM-MSCs (d) were treated with $6 \mathrm{mM} \mathrm{Ca}^{2+}$ medium and harvested at the indicated time points followed by Western blotting analysis. $\mathbf{c}$ The expression and secretion of OPN is induced by elevated extracellular $\mathrm{Ca}^{2+}$ specifically. Extracellular OPN levels were analyzed by ELISA after the C3H10T1/2 cells were incubated for $72 \mathrm{~h}$ as indicated. e Extracellular OPN and TGF $\beta 1$ level in the conditioned medium derived from different cultures of BM-MSCs as indicated. ${ }^{* *} p<0.001$ vs. first bar. ${ }^{\# \#} p<0.001$ vs. indicated group. ns not significant; nd not detected

than the levels of the minimum detectable dose $(<1 \mathrm{pg} / \mathrm{mL})$.

Using Western blot and ELISA assays, we confirmed that elevated extracellular $\mathrm{Ca}^{2+}$ increased OPN expression and secretion (Figs. 3b, c). Both precursor and secretory forms of OPN showed a continually increased expression after $24 \mathrm{~h}$ treatment in C3H10T1/2 cells (Fig. 3b). Expression of OPNs was also dramatically induced by elevated extracellular $\mathrm{Ca}^{2+}$ in BM-MSCs, but was not further increased after
$48 \mathrm{~h}$ of treatment (Fig. 3d). In parallel, the level of OPN in the conditioned medium peaked at $48 \mathrm{~h}$ and maintained up to $96 \mathrm{~h}$ in BM-MSCs (Fig. 3e). No increase occurred in TGF $\beta 1$ levels (Fig. 3e). Although FGF2 and TGF $\beta 1$ expressions were induced by elevated extracellular $\mathrm{Ca}^{2+}$, this may not be sufficient to alter the extracellular levels of these proteins. From these results, it appears that OPN meets the requirement as an autocrine or paracrine factor for MSCs under the elevated extracellular $\mathrm{Ca}^{2+}$ conditions. 
The secreted OPN by elevated extracellular $\mathrm{Ca}^{2+}$ does not affect cell proliferation and matrix mineralization

Since OPN is a well-known cytokine that plays an important role in cell proliferation, differentiation, and migration $^{28-30}$, we evaluated the role of the secreted OPNs on phenotype changes of MSCs under elevated extracellular $\mathrm{Ca}^{2+}$ conditions. We found that cell proliferation was not increased by the treatment of recombinant OPNs, while $6 \mathrm{mM} \mathrm{Ca}^{2+}$-medium potently enhanced cell proliferation (Fig. 4a). In addition, when secreted OPNs function was inhibited by adding an OPN neutralizing antibody (Fig. 4b and Supplementary Figure 4a) and also by OPN genes silencing (Supplementary Figure $4 \mathrm{~b}$ ), elevated extracellular $\mathrm{Ca}^{2+}$ sustains its ability to promote cell proliferation. FGF2 is a well-known growth factor promoting MSCs proliferation by inducting c-Jun and cyclin D1 expression ${ }^{26,31}$. We found that elevated extracellular $\mathrm{Ca}^{2+}$ strongly induced the levels of c-Jun, equivalent to those of the effective concentrations of FGF2 and TGF $\beta 1$ on cell proliferation (Fig. 4c and Supplementary Figure 5). However, there was no effect of OPN on both c-Jun and cyclin D1 expression (Fig. 4c), implying that OPN does not implicate in extracellular $\mathrm{Ca}^{2+}$-stimulated cell proliferation via c-Jun induction.

To investigate the role of the secreted OPN in matrix mineralization, cells were differentiated in osteogenic medium (OM) supplemented with recombinant OPNs. Matrix mineralization was not affected by supplementing with recombinant OPNs in both normal growth and osteogenic conditions (Fig. 4d). We also found that the supplementation of excess recombinant OPN did not enhance extracellular $\mathrm{Ca}^{2+}$-induced matrix mineralization (Fig. 4e). We suggest that the secreted OPN is not implicated in the promotion of cell proliferation or matrix mineralization under elevated extracellular $\mathrm{Ca}^{2+}$ conditions.

\section{The secreted OPN by elevated extracellular $\mathrm{Ca}^{2+}$ promotes MSCs migration}

To investigate the role of the secreted OPN in the elevated extracellular $\mathrm{Ca}^{2+}$-induced MSCs migration, we first examined whether $\mathrm{Ca}^{2+}$ per se acts as a chemoattractant. Transwell assay performed for short duration in the absence of OPN secretion under elevated extracellular $\mathrm{Ca}^{2+}$. Cells migrated toward the lower chamber containing the indicated concentration of $\mathrm{Ca}^{2+}$ after $1 \mathrm{~h}$ exposure and the number of migrated cells were continually increased up to $10 \mathrm{~h}$ (Fig. 5a). However, the number of migrated cells exposed to $6 \mathrm{mM} \mathrm{Ca}^{2+}$ medium was approximately equal to that of cells exposed to the standard medium, implying that $\mathrm{Ca}^{2+}$ itself could not promote cell migration. When exposed to the conditioned medium $(\mathrm{CM})$ obtained from 24 h-incubated cells under the elevated extracellular $\mathrm{Ca}^{2+}$ conditions, cells showed increased migration capacity at $6 \mathrm{~h}$ after treatment (Fig. 5b). The fresh medium supplemented with extracellular $\mathrm{Ca}^{2+}$ did not increase cell migration during this period. This effect of CM was also observed in BM-MSCs (Fig. 5c). When treated with elevated extracellular $\mathrm{Ca}^{2+}$ in the presence of cycloheximide, a protein synthesis inhibitor, we found that migrated cells were not increased and rather reduced when compared with control conditions (Fig. 5d). This result demonstrates again that newly synthesized proteins might involve in cell migration as well as cell proliferation. As the newly synthesized OPNs were secreted into culture medium under elevated extracellular $\mathrm{Ca}^{2+}$ conditions, the conditioned medium were depleted the secreted OPNs by using neutralizing anti-OPN antibodies before performing the Transwell assay. Cell migration induced by the elevated extracellular $\mathrm{Ca}^{2+}$-conditioned medium was significantly reduced by depletion of secreted OPNs (Fig. 5e). Moreover, the treatment of recombinant OPNs promoted cell migration of MSCs (Fig. 5f). TGF $\beta 1$ is as a potent chemokine of $\mathrm{MSCs}^{12}$. The degree of induction of cell migration by OPN was equivalent to that of TGF $\beta 1$ concentrations (Fig. $5 \mathrm{~g}$ ), suggesting that OPN secretion by MSCs under elevated extracellular $\mathrm{Ca}^{2+}$ represents a potent chemokine inducting MSCs migration. Based on these results, we concluded that elevated extracellular $\mathrm{Ca}^{2+}$ promotes cell migration via induction of expression and secretion of OPNs from MSCs stimulated by extracellular $\mathrm{Ca}^{2+}$.

\section{Release of calcium ions from calvarial bone slices by osteoclast-activated bone resorption affects MSCs phenotype}

This study was initiated by questioning whether the extracellular $\mathrm{Ca}^{2+}$ released from bone remodeling surface affects MSCs. Toward this end, we designed an in vitro osteoclast-mediated bone resorption assay using mouse calvaria bone slices. We confirmed that bone marrowderived precursor cells were stably attached to calvaria bone surface (Figs. 6b: $d, d^{\prime}$ and $g$ ), and then successfully differentiated into osteoclasts, which was determined by TRAP staining (Figs. 6a: $e$ and $e$ ). In addition, SEM image analysis demonstrated that osteoclast-activated bone resorption occurred successfully on the surface of calvaria bone slices (Figs. 6b: $e, e^{\prime}$ and $h$ ). We detected ionized calcium in the conditioned media, more importantly, which significantly increased in the osteoclastic BRCM (Fig. 6c). Because extracellular $\mathrm{Ca}^{2+}$ concentration started to increase after 8 days of incubation in BRCM, we concluded that this increase resulted from osteoclastmediated bone resorption (Fig. 6c). TGF $\beta 1$ was also released from osteoclast-activated bone slices as previously reported $^{12}$, albeit in small amounts (Supplementary Figure 6a). FGF2 was not detected in any conditioned media (Supplementary Figure 6a). Finally, we examined whether the released $\mathrm{Ca}^{2+}$ from bone slices can alter 

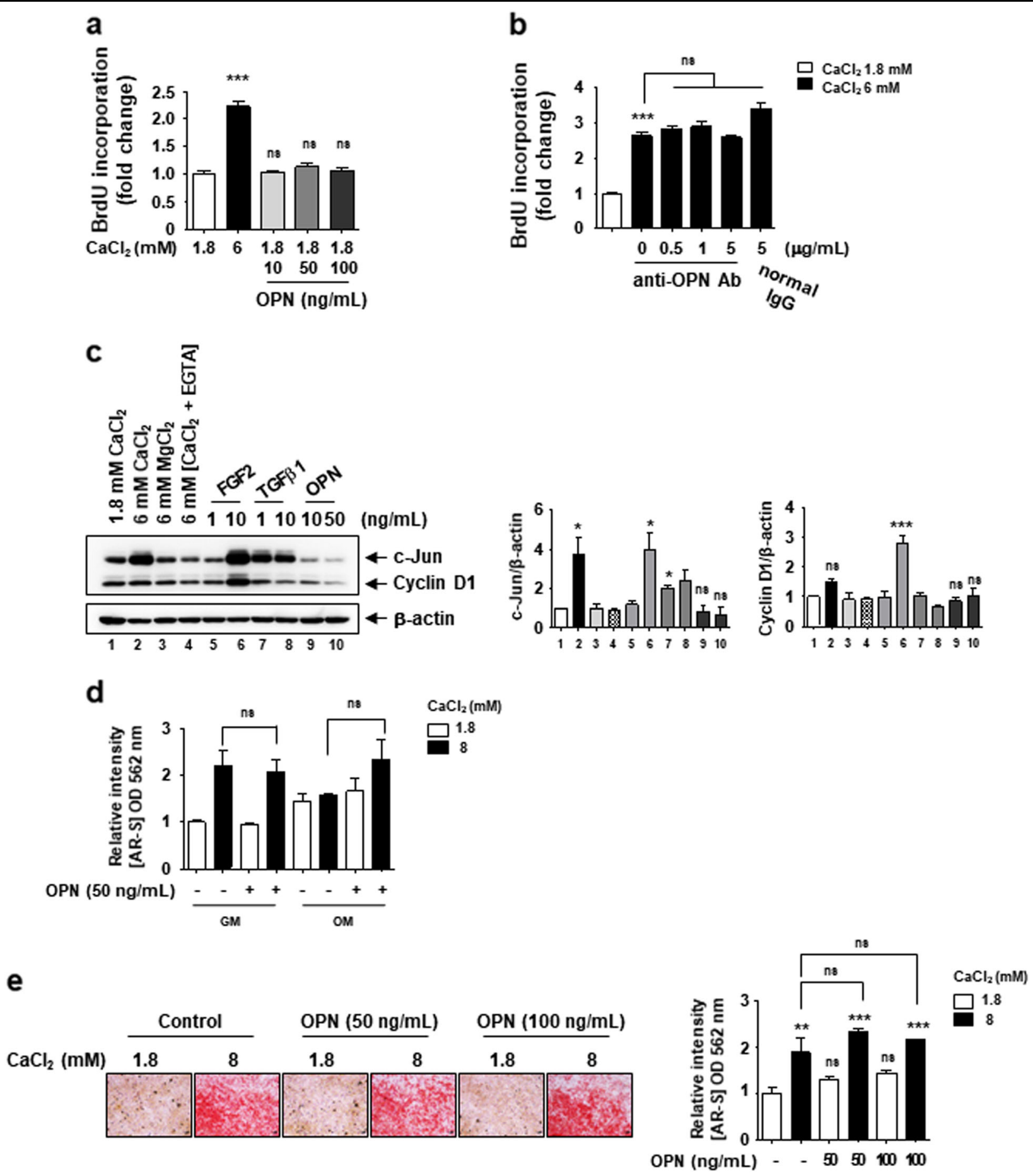

e

Fig. 4 Excessive extracellular OPN induced by elevated extracellular $\mathrm{Ca}^{2+}$ conditions does not affect cell proliferation and matrix mineralization. a The effect of recombinant OPN on cell proliferation. C3H10T1/2 cells were incubated in $6 \mathrm{mM} \mathrm{Ca}^{2+}$ medium or in the standard medium with the indicated amount of recombinant OPN, and cell proliferation was measured after $48 \mathrm{~h}$ treatment. $\mathbf{b}$ The effect of elevated extracellular $\mathrm{Ca}^{2+}$-induced cell proliferation is not affected by blocking the OPN action. After $48 \mathrm{~h}$ of treatment with the OPN neutralizing antibody and elevated extracellular $\mathrm{Ca}^{2+}$ medium, a BrdU incorporation assay was performed. Normal mouse lgG antibody was used as a control for antibody treatment. $\mathbf{c}$ Elevated extracellular $\mathrm{Ca}^{2+}$ increase c-Jun protein level. After $48 \mathrm{~h}$ of treatment as indicated, the relative expression of Cyclin D1 and c-Jun was calculated after normalization to $\beta$-actin. d The effect of recombinant OPN supplementation on matrix mineralization. C3H10T1/2 cells were incubated in normal growth medium (GM) or osteogenic medium (OM) supplemented with the indicated concentration of $\mathrm{CaCl}_{2}$ and recombinant OPN. Cells were subjected to AR staining after 16 days of differentiation and staining was quantified. e Supplementation of excess extracellular OPN has no effect on the elevated extracellular $\mathrm{Ca}^{2+}{ }_{\text {-induced }}$ matrix mineralization. $\mathrm{C}_{3} \mathrm{H} 10 \mathrm{~T} 1 / 2$ cells were incubated in $\mathrm{GM}$ supplemented with the indicated concentration of $\mathrm{CaCl}_{2}$ and recombinant OPN, and were subjected to AR staining at day 12 . The bar graph shows the relative intensity of AR staining. ${ }^{*} p<0.05$; ${ }^{* *} p<0.01 ;{ }^{* * *} p<0.001$ vs. first bar 

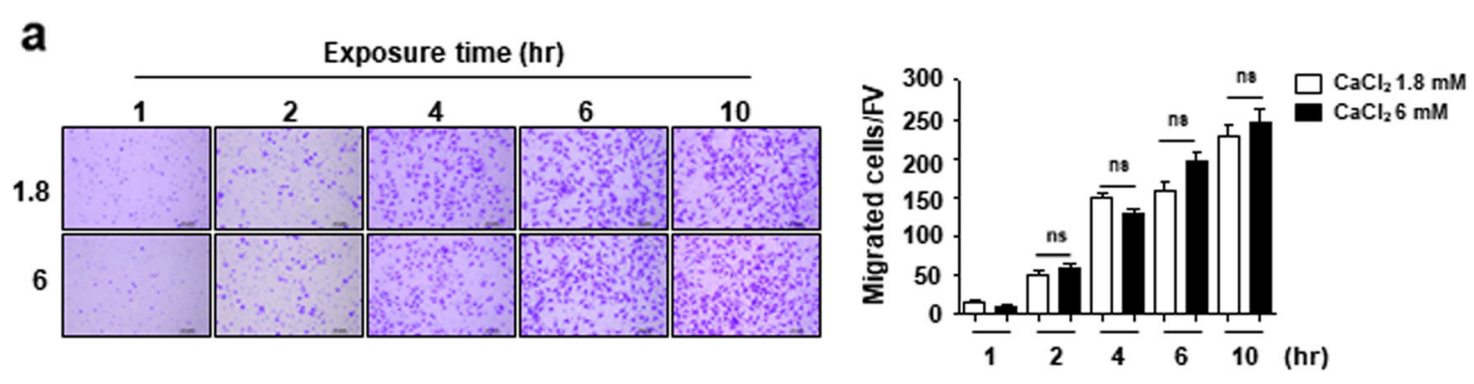

b
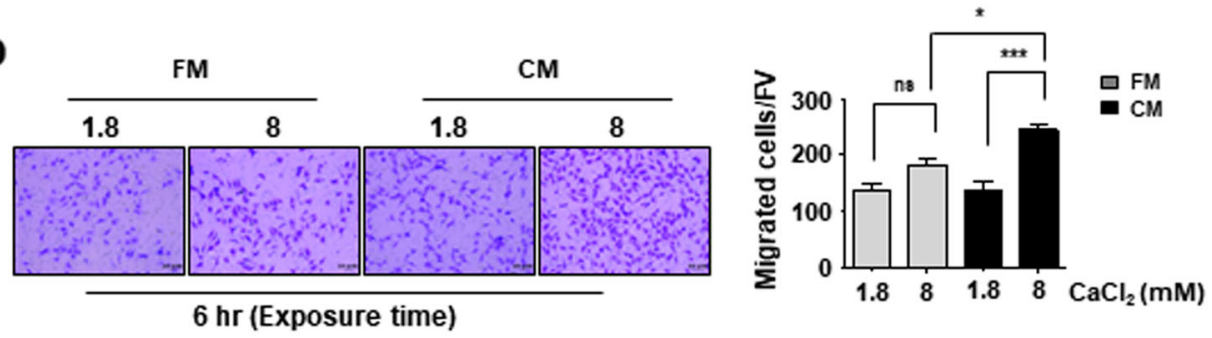

C
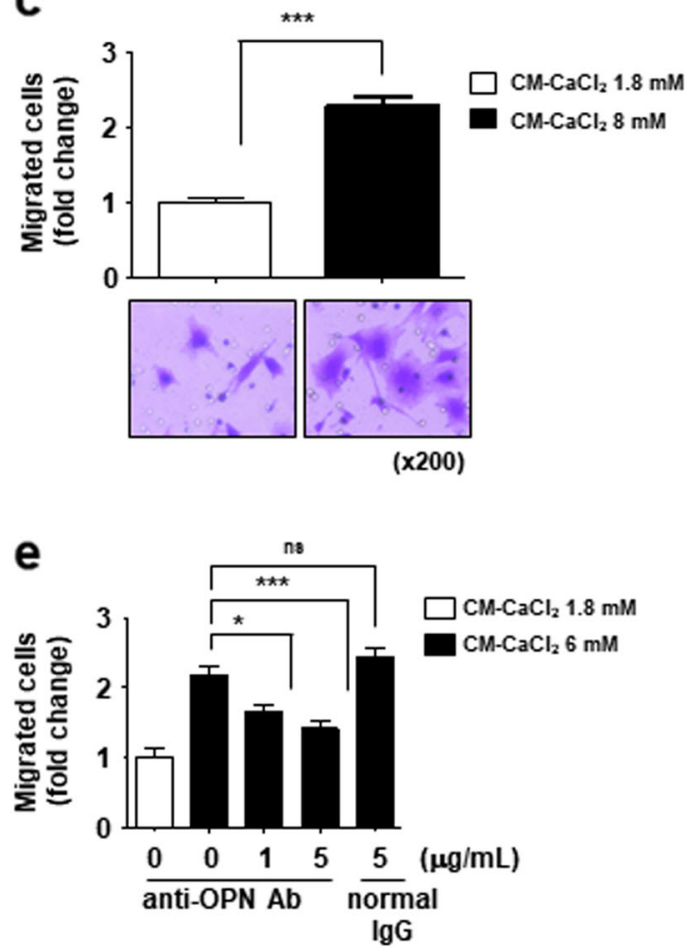

d
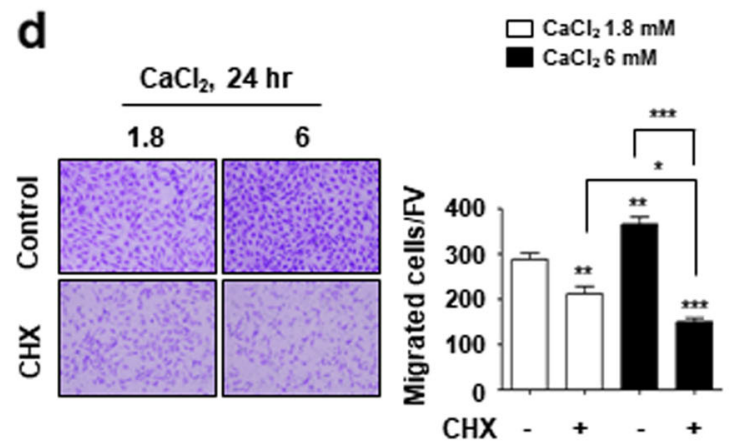

f

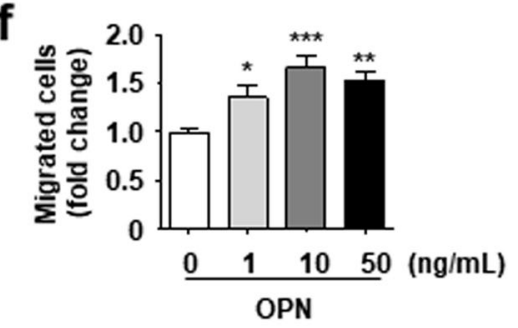

g

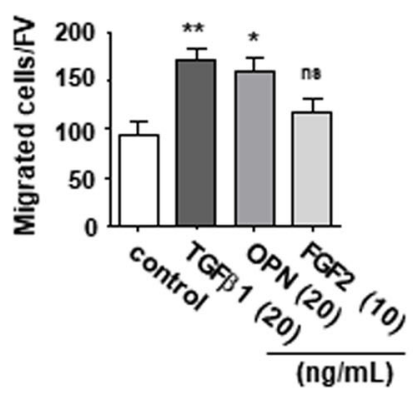

Fig. 5 (See legend on next page.) 
(see figure on previous page)

Fig. 5 Secreted OPN from MSCs acts as a chemotactic factor for MSCs under elevated extracellular $\mathrm{Ca}^{2+}$ conditions. a Extracellular $\mathrm{Ca}^{2+}$ itself does not act as a cellular chemoattractant. C3H10T1/2 cells were used in Transwell assay with standard medium or 6 mM Ca ${ }^{2+}$ medium in the lower chamber. Cells that migrated to the lower side of the well for the indicated time were fixed and stained. $\mathbf{b}$ and $\mathbf{c}$ Conditioned medium (CM) from $\mathrm{C} 3 \mathrm{H} 10 \mathrm{~T} 1 / 2$ cells cultured under the elevated extracellular $\mathrm{Ca}^{2+}$ condition induces cell migration. $\mathbf{b}$ Migration of $\mathrm{C} 3 \mathrm{H} 10 \mathrm{~T} 1 / 2$ cells for $6 \mathrm{~h}$ to the lower chamber containing the indicated medium. Standard medium supplemented with the indicated concentration of $\mathrm{CaCl}_{2}$ (fresh medium, $\mathrm{FM}$ ) was used as a control. c Migration of BM-MSCs for $6 \mathrm{~h}$ to the lower chamber containing in the indicated medium. $\mathbf{d}$ Migration inducible ability of CM is abolished following inhibition of new protein synthesis. C3H10T1/2 cells were seeded with or without $5 \mu \mathrm{g} / \mathrm{mL}$ of cycloheximide (CHX) in the upper chamber. Cells that migrated to the lower side of the well for $24 \mathrm{~h}$ were fixed and stained. e-g Extracellular OPN enhances migration of MSCs. e Depletion of OPN in the CM by using neutralizing antibodies abolishes the elevated extracellular $\mathrm{Ca}^{2+}$-induced cell migration. The indicated $\mathrm{CM}$ was pre-incubated with an OPN neutralizing antibody for $1 \mathrm{~h}$ and used as the lower chamber medium. C3H10T1/2 cells that migrated to the lower side of the well for $6 \mathrm{~h}$ were fixed and stained. $\mathbf{f}$ Migration of C3H10T1/2 cells for $6 \mathrm{~h}$ to the lower chamber containing the indicated amount of recombinant OPN in standard medium. Number of migrated cells expressed as fold increases relative to control (e and $\mathbf{f}$ ). $\mathbf{g}$ Migration of BM-MSCs for $4 \mathrm{~h}$ to the lower chamber containing $0.1 \%$ BSA (control), $20 \mathrm{ng} / \mathrm{mL}$ TGF $\beta 1,20 \mathrm{ng} / \mathrm{mL}$ OPN, or $10 \mathrm{ng} / \mathrm{mL}$ FGF2. Number of migrated cells per field of view (FV, $\times 50$ magnification) is indicated $(\mathbf{a}, \mathbf{b}, \mathbf{d}$, and $\mathbf{g})$. Number of migrated cells expressed as the fold increases relative to control (c, e, and $\mathbf{f}) .{ }^{*} p<$ $0.05 ;{ }^{* *} p<0.01$; ${ }^{* * *} p<0.001$ vs. indicated group. $p<0.001$ (a-e). ${ }^{*} p<0.05 ;{ }^{* *} p<0.01$; ${ }^{* * *} p<0.001$ vs. first bar (f and $\mathbf{g}$ )

MSCs phenotype. Corresponding to the data from Fig. 6c, the 12th and 16th days of BRCMs induced OPNs secretion from BM-MSCs (Fig. 6d). BRCM on day 16 was found to increase cell proliferation of BM-MSCs (Fig. 6e). These results suggest that elevated extracellular $\mathrm{Ca}^{2+}$ in BRCMs induces BM-MSCs to express and secrete OPN, as well as cell proliferation. Finally, BM-MSCs' culture medium treated with the 16th days of BRCM was used for the migration assay; we named BM-MSCs' culture medium treated with BRCM as "BRCM-treated CM". We found that cell migration was significantly increased by the BRCM-treated CM comparing to the BCCM-treated $\mathrm{CM}$ (Fig. 6f). Moreover, cell migration induced by the BRCM-treated CM was significantly abolished by OPN neutralizing antibody (Fig. 6f). BRCM-treated CM from the 4th days did not promote cell migration at all (Supplementary Figure 6c). These observations suggest that expression and secretion of OPNs from MSCs stimulated by extracellular $\mathrm{Ca}^{2+}$ trigger MCSs migration. Altogether, we conclude that the extracellular $\mathrm{Ca}^{2+}$ released from bone remodeling surface can affect the MSCs phenotype during osteoclast-mediated bone resorption.

\section{Discussion}

A continuous supply of MSCs in bone remodeling is a prerequisite for bone homeostasis. Although TGF $\beta 1$ has been known as a major factor triggering MSCs recruitment, understanding the homing and expansion of MSCs to the bone remodeling sites remains an important challenge. Here, we suggest that the ionized calcium derived from bone remodeling surface following osteoclastmediated bone resorption is an important factor underlying the supplementation of MSCs to the bone remodeling site. We showed for the first time that $\mathrm{Ca}^{2+}$ is released from bone by osteoclast-mediated bone resorption, which results in the elevation of extracellular $\mathrm{Ca}^{2+}$ concentration leading to phenotypical changes in proximal MSCs involving cell proliferation and migration (Fig. 6g).
We found that the elevated extracellular $\mathrm{Ca}^{2+}$ induced expressions of not only cell growth factors, FGF2 and TGF $\beta 1$, but also the levels of cell cycle regulator, c-Jun. Therefore, we expected that these factors might mediate the elevated extracellular $\mathrm{Ca}^{2+}$-induced cell proliferation. However, the levels of secreted TGF $\beta 1$ and FGF2 did not increase in the conditioned medium, suggesting that their expression induced by elevated extracellular $\mathrm{Ca}^{2+}$ was insufficient to alter MSCs phenotype. In addition, FGF2 had little effect on MSCs proliferation at levels below 1 $\mathrm{ng} / \mathrm{mL}$ (Supplementary Figure 5). Thus, we assume that TGF $\beta 1$ or FGF2 played no role in the elevated extracellular $\mathrm{Ca}^{2+}$-induced cell proliferation or c-Jun expression in this experiment. In the in vitro osteoclastmediated bone resorption assay, the level of TGF $\beta 1$ and FGF2 did not significantly change in the conditioned medium (Supplementary Figure 6a). Meanwhile, MSCs exposed to the conditioned medium obtained from active osteoclasts (OCCM and BRCM) showed a dramatic increase in cell proliferation (Supplementary Figure 6b), implying that not only $\mathrm{Ca}^{2+}$ from bone but also other factors derived from active osteoclasts could affect MSCs proliferation. In conjunction with our finding that the elevated extracellular $\mathrm{Ca}^{2+}$ increases MSCs migration, we suggest the presence of a positive feedback loop involving cell proliferation and cell recruitment in the proximal microenvironment of the bone remodeling site (Fig. $6 \mathrm{~g}$ ). Extracellular $\mathrm{Ca}^{2+}$ and TGF $\beta 1$ derived from bone matrix and secretory factors derived from osteoclast might orchestrate MSCs recruitment and proliferation, although the molecular details of this cooperation remain to be elucidated. We believe that this is an important mechanism underlying the continuous supply of MSCs for bone remodeling. In the current study, however, we did not evaluate the comparative potency of bone-derived TGF $\beta 1$, extracellular $\mathrm{Ca}^{2+}$, and osteoclast-derived factors in inducing cell proliferation and cell recruitment at bone resorption sites. Since we found that MSCs proliferation is 
sensitive to changes in extracellular $\mathrm{Ca}^{2+}$ concentration (Fig. 1a) and both OPN and TGF $\beta 1$ had similar capacity to induce cell migration (Fig. $5 \mathrm{~g}$ ), we speculate that the role of elevated extracellular $\mathrm{Ca}^{2+}$ in homing and expansion of the MSCs might be significant in bone remodeling surface. Related to this issue, further studies are needed.

Another important finding of this study relates to the role of extracellular $\mathrm{Ca}^{2+}$ concentration in cell migration via OPN expression. OPN is an indicator of osteogenic differentiation due to its expression in the initial stages of matrix mineralization ${ }^{32}$. Meanwhile, extracellular OPN is known to interact with multiple cell surface receptors, including Integrin and CD44, resulting in cell adhesion, survival, and migration ${ }^{28,33,34}$. Indeed, the role of OPN in MSCs migration has been suggested in the previous study, showing the involvement of FAK, ERK, and Integrin $\beta 1$ pathways ${ }^{35,36}$. However, there has been no report showing whether OPN expression is necessary or how its expression is regulated during MSCs migration. To our knowledge, this is the first study suggesting OPN expression is induced by extracellular $\mathrm{Ca}^{2+}$ to regulate cell migration. We have not investigated whether OPN induces MSCs migration via interaction with cell surface receptors under elevated extracellular $\mathrm{Ca}^{2+}$ conditions. Given that extracellular $\mathrm{Ca}^{2+}$ suppresses cell adhesion by attenuating the binding affinity of OPN to Integrin $\alpha_{\mathrm{v}} \beta_{3}{ }^{37}$, it will be worthwhile to study the OPN-mediated regulation of

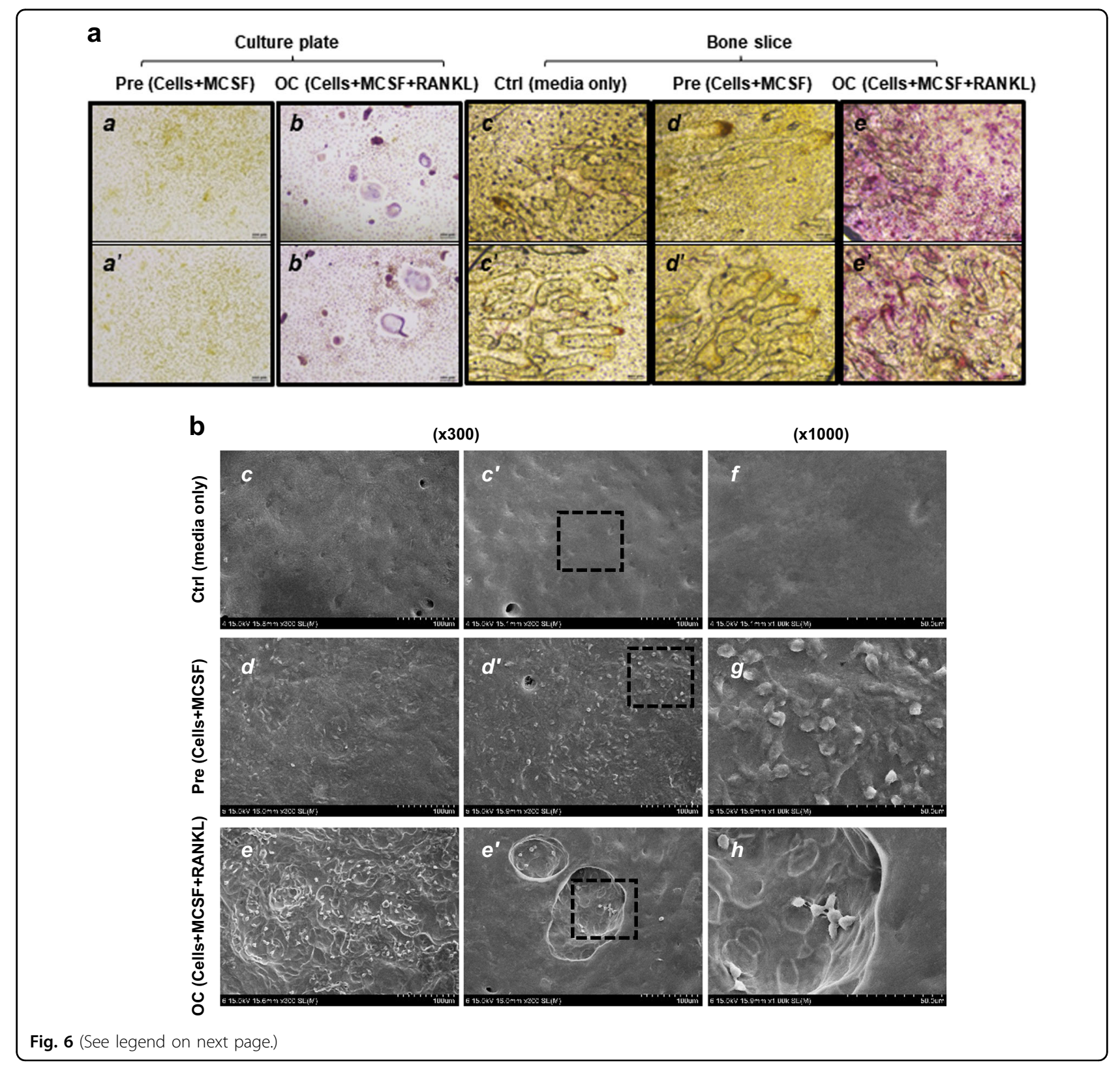




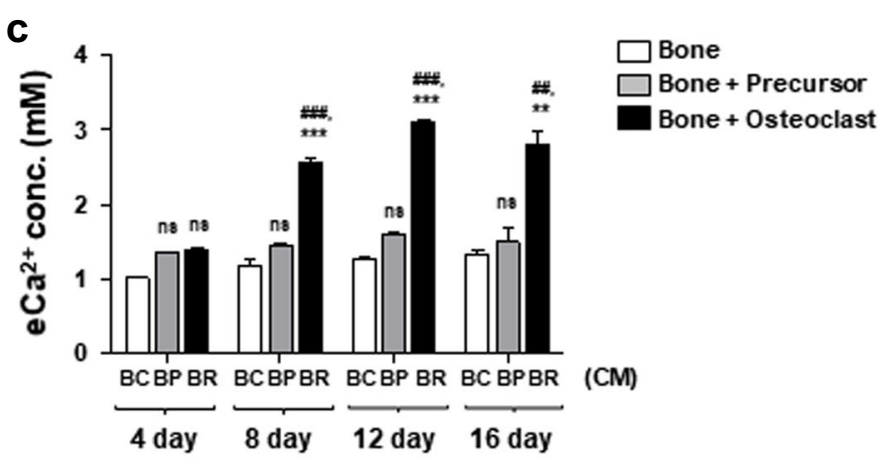

d Culture medium of BM-MSCs

e

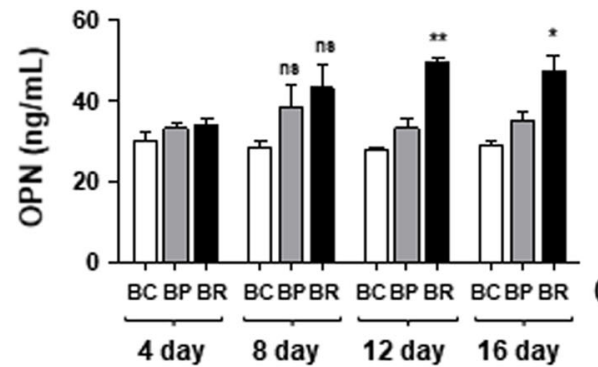

(CM)

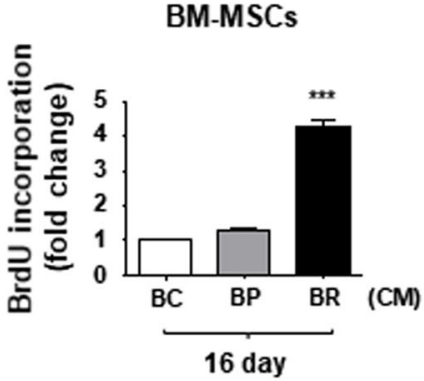

f
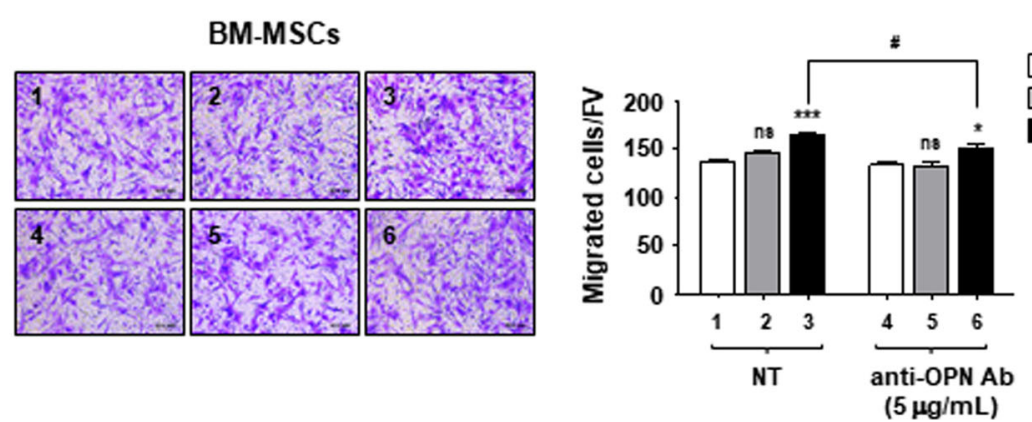

g

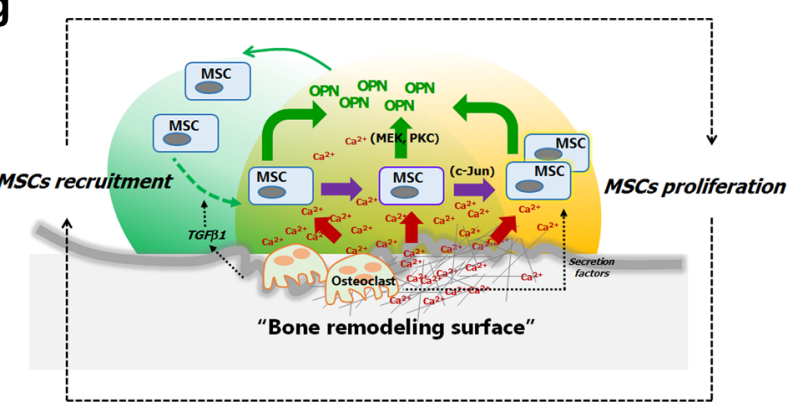

Fig. 6 (See legend on next page.)

cell migration under elevated extracellular $\mathrm{Ca}^{2+}$ conditions.

OPN is abundantly secreted by $\mathrm{MSCs}^{30}$, but little is known about the regulation of its expression. Here, we suggest that extracellular $\mathrm{Ca}^{2+}$ concentration regulates OPN expression via activation of MEK and PKC pathways (Supplementary Figure 7a). Several types of cells sense extracellular $\mathrm{Ca}^{2+}$ via calcium sensing receptor $(\mathrm{CaSR})^{38-}$
40. The CaSR is a G protein-coupled receptor that is linked to several intracellular signaling cascades such as PLC-PKC pathway, calmodulin-mediated pathway, and MAPK pathway ${ }^{39}$. This receptor is expressed in bone sections containing osteoclasts, osteoblasts, and MSCs $^{38,41-43}$, and conditional CaSR-knockout resulted in altered bone formation via changing in differentiation of osteoblast and osteoclast ${ }^{41,44}$. However, there are 
(see figure on previous page)

Fig. 6 Increased extracellular $\mathrm{Ca}^{2+}$ in osteoclast-activated bone resorption conditioned medium affect MSCs phenotype. a Preparation of osteoclastic bone resorption conditioned medium. Osteoclastic precursors isolated from mouse bone marrow were cultured on mouse calvairal bone slices in the presence of MCSF and RANKL to induce osteoclast differentiation (OC), or with only MCSF as a control (Pre). To monitor morphological change of precursors and determine osteoclast differentiation, precursors were cultured under the same condition without bone slices $(\boldsymbol{a}, \boldsymbol{b})$. After 16 days of incubation, cells were stained for TRAP activity. Precursors and bone slice only showed TRAP-negative $\left(\boldsymbol{a}, \boldsymbol{a}^{\prime}, \boldsymbol{c}, \boldsymbol{c}^{\prime}, \boldsymbol{d}, \boldsymbol{d}\right)$, and active osteoclast revealed TRAP-positive $\left(\boldsymbol{b}, \boldsymbol{b}^{\prime}, \boldsymbol{e}, \boldsymbol{e}\right)$. Image, x100 magnification. $\mathbf{b}$ Analysis of bone surface topology by using scanning electronic microscopy (SEM). SEM image showed a rough bone surface with several dimples by the osteoclast-activated bone resorption (e, $\left.\boldsymbol{e}^{\prime}, \boldsymbol{h}\right)$. Bone slice surface in the presence of media alone was clean without any cells and dents $\left(\boldsymbol{c}, \boldsymbol{c}^{\prime}, \boldsymbol{f}\right)$. Image, $\times 300$. The 1000x magnification images represent dotted rectangle boxes. c After collecting the bone resorption conditioned medium as described in Materials and methods section, the extracellular $\mathrm{Ca}^{2+}$ concentration was analyzed. BCCM bone control-conditioned medium, BPCM precursor with bone-conditioned medium, BRCM osteoclast-activated bone resorption-conditioned medium. $\mathbf{d}$ BRCM induces secretion of OPN in BM-MSCs. BM-MSCs were treated with the indicated bone resorptionconditioned media $(4,8,12$, and 16 th day) for $48 \mathrm{~h}$. Culture medium was collected and used for ELISA to measure secreted OPN levels. e BRCM increases cell proliferation of BM-MSCs. Cells were incubated in the indicated conditioned medium, and cell proliferation was measured by BrdU assay after $48 \mathrm{~h}$ treatment. $\mathbf{f}$ BRCM-treated culture medium (CM) enhances the migration of BM-MSCs. BRCM-treated CM from the 16th days was loaded in the lower chamber. To neutralize secreted OPN, the indicated CMs were pre-incubated with individual neutralizing antibodies for $1 \mathrm{~h}$ and used as the medium for the lower chamber. Migration of BM-MSCs for $6 \mathrm{~h}$ to the lower chamber were visualized with staining (left). Number of migrated cells per field of view (FV, x50 magnification) is expressed (right). $\mathbf{g}$ Working model illustrating the role of ionized calcium in bone remodeling surface. ${ }^{* *} p<0.01 ;{ }^{* * *} p<0.001$ vs. BCCM. ${ }^{\# \#} p<0.01 ;{ }^{\# \# \#} p<0.001$ vs. BPCM. ${ }^{* * *} p<0.001$ vs. first bar

conflicting reports regarding the CaSR-dependent or independent response of bone cells to extracellular $\mathrm{Ca}^{2+17,20,21}$. In line with other reports ${ }^{45,46}$, we observed that the expression of CaSR in MSCs and pre-osteoblast (MC3T3-E1) cells is very low, and was hardly detected using RT-PCR (Supplementary Figure 7b). Moreover, CaSR silencing failed to affect the extracellular $\mathrm{Ca}^{2}$ ${ }^{+}$-induced OPN expression (Supplementary Figure 7c). Although PKC or MEK pathway activity is required for OPN expression under elevated extracellular $\mathrm{Ca}^{2+}$ conditions, CaSR may not mediate its activity in MSCs. Instead, we found that polycystin 2 (PC2), a calcium channel protein, partially regulates the extracellular $\mathrm{Ca}^{2}$ ${ }^{+}$-induced OPN expression (Supplementary Figure 7d). A recent study suggested that Connexin 43 (Cx43), known as gap junction protein, has an important role in osteogenic differentiation capacity of human MSCs in response to extracellular $\mathrm{Ca}^{2+47}$. $\mathrm{N}$-type and P-type voltage-gated calcium channels (VGCCs) are also potential candidates, as they respond to extracellular $\mathrm{Ca}^{2+}$ and determine the osteoblast phenotype ${ }^{20,48}$. Therefore, we are focusing on these proteins (PC2, Cx43, and VGCCs) as candidates of relevance in altered MSC phenotype in response to extracellular $\mathrm{Ca}^{2+}$ concentration. Further studies are needed to fully understand how MSCs sense extracellular $\mathrm{Ca}^{2+}$ change at the bone remodeling site.

There are several reports showing the effect of extracellular $\mathrm{Ca}^{2+}$ on the osteogenic differentiation potential of precursor cells. We found that the elevated extracellular $\mathrm{Ca}^{2+}$ dramatically increased matrix mineralization in both growth and osteogenic conditions. However, enhanced matrix mineralization by extracellular $\mathrm{Ca}^{2+}$ was restricted to specific $\mathrm{Ca}^{2+}$ concentrations under osteogenic induction conditions. There are reports that higher ionic strength tends to increase the detachment of matrix proteins from the substrate ${ }^{19,49}$, suggesting that the balance between the secreted proteins by osteogenic cells and the detachment of precipitated matrix proteins by $\mathrm{Ca}^{2}$ + is critical for the regulation of matrix mineralization. Therefore, the differential effect of extracellular $\mathrm{Ca}^{2+}$ on matrix mineralization may be attributed to the role of high extracellular $\mathrm{Ca}^{2+}$ concentrations in segregating the precipitated matrix proteins secreted by osteoblastic cells. The question remains regarding how the elevated extracellular $\mathrm{Ca}^{2+}$ promote matrix mineralization in both growth and osteogenic conditions. Considering the previous study showing that OPN supplementation potentiates matrix mineralization of $\mathrm{MSCs}^{30}$, we surmised that matrix mineralization might be promoted by OPN induction. However, the supplementation of recombinant OPNs in either normal growth medium or osteogenic induction medium did not promote matrix mineralization (Figs. 4d, e). There are reports showing that elevated extracellular $\mathrm{Ca}^{2+}$ induces matrix mineralization in smooth muscle cells and in osteoblasts under the absence of osteogenic factor conditions, which were attributed to increased expression of Pit-1, Integrin $\beta 1$, Connexin 43 (Cx43), Angiopoietin-1, and Angiopoientin-2 ${ }^{19,50}$. We found that $\mathrm{Cx} 43$ and Pit1 expression was significantly increased by elevated extracellular $\mathrm{Ca}^{2+}$, whereas Integrin $\beta 1$ expression was not affected (Supplementary Figure 2b). Expression of Angiopoientin-1 and -2, was not induced by elevated extracellular $\mathrm{Ca}^{2+}$ (data not shown). Given the finding that Pit1 and $\mathrm{Cx} 43$ expression was increased by elevated extracellular $\mathrm{Ca}^{2+}$ in both growth and osteogenic conditions (Supplementary Figure $2 \mathrm{~b}$ ), it would be worth to evaluate whether these factors can be implicated in extracellular $\mathrm{Ca}^{2+}$-mediated matrix mineralization in BM-MSCs. Regarding this issue, a further study is needed to address these outstanding questions.

We believe that MSCs may sense the elevated levels of extracellular $\mathrm{Ca}^{2+}$ for the expansion of MSCs to meet the 
basic requirements of bone formation. Moreover, OPN secreted from MSCs by elevated extracellular $\mathrm{Ca}^{2+}$ may function as a chemoattractant in recruiting MSCs to the proximal sites of bone resorption. Many studies have demonstrated the chemoattractant properties of OPN in a variety of cell types in response to injury and inflammation $^{51,52}$. Considering the previous reports that OPN was elevated at a fracture site and in damaged bone matrix $^{53,54}$, our finding supports the notion that OPN plays an important role in the recruitment of MSCs to the site of bone remodeling. Here, we would like to emphasize that the production of OPN can be induced by the elevated extracellular $\mathrm{Ca}^{2+}$-stimulated BM-MSCs, and not from the bone matrix or resident bone cells such as osteocytes. We believe that this may help to propagate the signal as to where and how many BM-MSCs are required for accurate bone remodeling by using the stimulated BM-MSCs as an intermediates. Although our findings are from in vitro experiments, we hope that this study elucidating the features and potential of BM-MSCs will provide the groundwork for future in vivo studies to facilitate the optimization of bone regeneration strategies.

\section{Acknowledgements}

We thank the High Resolution Scanning Electron Microscope Core at the Korea Basic Science Institute (KBSI, Gwangju) for technical assistance with SEM image analysis. This work was supported by National Research Foundation of Korea (NRF) grants funded by the Korean government (MSIT) (2011-0030121, 2017R1A2B2008167) and Basic Science Research Program through the NRF funded by the Ministry of Education (NRF-2016R1A6A3A11930316).

\section{Author details \\ ${ }^{1}$ Research Center for Biomineralization Disorders, School of Dentistry, Chonnam National University, Gwangju, Republic of Korea. ${ }^{2}$ Department of Pharmacology and Dental Therapeutics, School of Dentistry, Chonnam National University, Gwangju, Republic of Korea. ${ }^{3}$ School of Biological Sciences and Biotechnology, Chonnam National University, Gwangju, Republic of Korea. ${ }^{4}$ Department of Biological Sciences, Chonnam National University, Gwangju, Republic of Korea}

\section{Conflict of interest}

The authors declare that they have no conflict of interest.

\section{Publisher's note}

Springer Nature remains neutral with regard to jurisdictional claims in published maps and institutional affiliations.

Supplementary information accompanies this paper at https://doi.org/ 10.1038/s12276-018-0170-6.

Received: 21 February 2018 Revised: 30 May 2018 Accepted: 12 July 2018. Published online: 5 November 2018

\section{References}

1. Feng, X. \& McDonald, J. M. Disorders of bone remodeling. Annu Rev. Pathol. 6, 121-145 (2011)

2. Nakashima, T., Hayashi, M. \& Takayanagi, H. New insights into osteoclastogenic signaling mechanisms. Trends Endocrinol. Metab. 23, 582-590 (2012).
3. Park, D. et al. Endogenous bone marrow MSCs are dynamic, fate-restricted participants in bone maintenance and regeneration. Cell Stem Cell 10, 259-272 (2012).

4. Kitaori, T. et al. Stromal cell-derived factor 1/CXCR4 signaling is critical for the recruitment of mesenchymal stem cells to the fracture site during skeletal repair in a mouse model. Arthritis Rheum. 60, 813-823 (2009).

5. Tewari, D. et al. Ovariectomized rats with established osteopenia have diminished mesenchymal stem cells in the bone marrow and impaired homing, osteoinduction and bone regeneration at the fracture site. Stem Cell Rev. 11, 309-321 (2015).

6. Crane, J. L. \& Cao, X. Bone marrow mesenchymal stem cells and TGF- $\beta$ signaling in bone remodeling. J. Clin. Invest 124, 466-472 (2014).

7. Crane, J. L. \& Cao, X. Function of Matrix IGF-1 in coupling bone resorption and formation. J. Mol. Med. 92, 107-115 (2014).

8. Kular, J., Tickner, J., Chim, S. M. \& Xu, J. An overview of the regulation of bone remodelling at the cellular level. Clin. Biochem. 45, 863-873 (2012).

9. Bismar, $H$. et al. Transforming growth factor $\beta$ (TGF- $\beta$ ) levels in the conditioned media of human bone cells: relationship to donor age, bone volume, and concentration of TGF- $\beta$ in human bone matrix in vivo. Bone 24, 565-569 (1999).

10. Linkhart, T. A., Mohan, S. \& Baylink, D. J. Growth factors for bone growth and repair: IGF, TGF $\beta$ and BMP. Bone 19 (1 Suppl), S1-S12 (1996).

11. Seyedin, S. M., Thomas, T. C., Thompson, A. Y., Rosen, D. M. \& Piez, K. A. Purification and characterization of two cartilage-inducing factors from bovine demineralized bone. Proc. Natl Acad. Sci. U.S.A. 82, 2267-2271 (1985).

12. Tang, $Y$. et al. TGF- $\beta 1$-induced migration of bone mesenchymal stem cells couples bone resorption and formation. Nat. Med. 15, 757-765 (2009).

13. Ponte, A. L. et al. The in vitro migration capacity of human bone marrow mesenchymal stem cells: comparison of chemokine and growth factor chemotactic activities. Stem Cells 25, 1737-1745 (2007).

14. Silver, I. A., Murrills, R. J. \& Etherington, D. J. Microelectrode studies on the acid microenvironment beneath adherent macrophages and osteoclasts. Exp. Cell Res. 175, 266-276 (1988)

15. Sun, X., Kishore, V., Fites, K. \& Akkus, O. Osteoblasts detect pericellular calcium concentration increase via neomycin-sensitive voltage gated calcium channels. Bone 51, 860-867 (2012).

16. Chai, Y. C. et al. Current views on calcium phosphate osteogenicity and the translation into effective bone regeneration strategies. Acta Biomater. 8, 3876-3887 (2012).

17. $\mathrm{Hu}, \mathrm{F}$. et al. Elevation of extracellular $\mathrm{Ca}(2+)$ induces store-operated calcium entry via calcium-sensing receptors: a pathway contributes to the proliferation of osteoblasts. PLOS ONE 9, e107217 (2014).

18. Maeno, S. et al. The effect of calcium ion concentration on osteoblast viability, proliferation and differentiation in monolayer and 3D culture. Biomaterials $\mathbf{2 6}$, 4847-4855 (2005)

19. Nakamura, S. et al. Effect of calcium ion concentrations on osteogenic differentiation and hematopoietic stem cell niche-related protein expression in osteoblasts. Tissue Eng. Part A 16, 2467-2473 (2010).

20. Barradas, A. M. et al. A calcium-induced signaling cascade leading to osteogenic differentiation of human bone marrow-derived mesenchymal stromal cells. Biomaterials 33, 3205-3215 (2012).

21. González-Vázquez, A., Planell, J. A. \& Engel, E. Extracellular calcium and CaSR drive osteoinduction in mesenchymal stromal cells. Acta Biomater. 10, 2824-2833 (2014)

22. Hashimoto, R. et al. Increased extracellular and intracellular $\mathrm{Ca}^{2+}$ lead to adipocyte accumulation in bone marrow stromal cells by different mechanisms. Biochem Biophys. Res. Commun. 457, 647-652 (2015).

23. Lei, Q. et al. Proteomic analysis of the effect of extracellular calcium ions on human mesenchymal stem cells: Implications for bone tissue engineering. Chem. Biol. Interact. 233, 139-146 (2015).

24. Mellor, L. F. et al. Extracellular calcium modulates chondrogenic and osteogenic differentiation of human adipose-derived stem cells: a novel approach for osteochondral tissue engineering using a single stem cell source. Tissue Eng. Part A 21, 2323-2333 (2015).

25. Jeong, B. C., Kang, I. H., Hwang, Y. C., Kim, S. H. \& Koh, J. T. MicroRNA-194 reciprocally stimulates osteogenesis and inhibits adipogenesis via regulating COUP-TFIl expression. Cell Death Dis. 5, e1532 (2014).

26. Lee, M. N. et al. FGF2 stimulates COUP-TFII expression via the MEK1/2 pathway to inhibit osteoblast differentiation in C3H10T1/2 cells. PLoS One 11, e0159234 (2016). 
27. Cheng, S. et al. Effects of extracellular calcium on viability and osteogenic differentiation of bone marrow stromal cells in vitro. Hum. Cell 26, 114-120 (2013).

28. Kahles, F., Findeisen, H. M. \& Bruemmer, D. Osteopontin: A novel regulator at the cross roads of inflammation, obesity and diabetes. Mol. Metab. 3, 384-393 (2014).

29. Wei, R., Wong, J. P. C. \& Kwok, H. F. Osteopontin-a promising biomarker for cancer therapy. J. Cancer 8, 2173-2183 (2017).

30. Chen, Q. et al. An osteopontin-integrin interaction plays a critical role in directing adipogenesis and osteogenesis by mesenchymal stem cells. Stem Cells 32, 327-337 (2014)

31. Frederick, T. J., Min, J., Altieri, S. C., Mitchell, N. E. \& Wood, T. L. Synergistic induction of cyclin D1 in oligodendrocyte progenitor cells by IGF-I and FGF-2 requires differential stimulation of multiple signaling pathways. Glia $\mathbf{5 5}$, 1011-1022 (2007).

32. Denhardt, D. T. \& Noda, M. Osteopontin expression and function: Role in bone remodeling. J. Cell Biochem Suppl. 30-31, 92-102 (1998).

33. Hu, D. D., Lin, E. C., Kovach, N. L., Hoyer, J. R. \& Smith, J. W. A biochemical characterization of the binding of osteopontin to integrins av $\beta 1$ and $a v \beta 5$. J. Biol. Chem. 270, 26232-26238 (1995).

34. Wang, K. X. \& Denhardt, D. T. Osteopontin: Role in immune regulation and stress responses. Cytokine Growth Factor Rev. 19, 333-345 (2008).

35. Zou, C. et al. Osteopontin promotes mesenchymal stem cell migration and lessens cell stiffness via Integrin $\beta 1, F A K$, and ERK pathways. Cell Biochem Biophys. 65, 455-462 (2013).

36. Zou, C., Song, G., Luo, Q., Yuan, L. \& Yang, L. Mesenchymal stem cells require integrin $\beta 1$ for directed migration induced by osteopontin in vitro. Vitr. Cell Dev. Biol. Anim. 47, 241-250 (2011).

37. Hu, D. D., Hoyer, J. R. \& Smith, J. W. Ca2+suppresses cell adhesion to osteopontin by attenuating binding affinity for integrin avß3. J. Bio Chem. 270, 9917-9925 (1995).

38. Goltzman, D. \& Hendy, G. N. The calcium-sensing receptor in bone-mechanistic and therapeutic insights. Nat. Rev. Endocrinol. 11, 298-307 (2015).

39. Hofer, A. M. \& Brown, E. M. Extracellular calcium sensing and signalling. Nat. Rev. Mol. Cell Biol. 4, 530-538 (2003).

40. Tharmalingam, S. \& Hampson, D. R. The calcium-sensing receptor and integrins in cellular differentiation and migration. Front Physiol. 7, 190 (2016).
41. Chang, W., Tu, C., Chen, T. H., Bikle, D. \& Shoback, D. The extracellular calciumsensing receptor (CaSR) is a critical modulator of skeletal development. Sci. Signal 1, ra1 (2008).

42. Marie, P. J. The calcium-sensing receptor in bone cells: A potential therapeutic target in osteoporosis. Bone 46, 571-576 (2010).

43. Dvorak, M. M. \& Riccardi, D. Ca2+as an extracellular signal in bone. Cell Calcium 35, 249-255 (2004)

44. Dvorak-Ewell, M. M. et al. Osteoblast extracellular $\mathrm{Ca}(2+)$-sensing receptor regulates bone development, mineralization and turnover. J. Bone Miner. Res 26, 2935-2947 (2011).

45. Gabusi, E. et al. Extracellular calcium chronically induced human osteoblasts effects: Specific modulation of osteocalcin and collagen type XV. J. Cell Physiol. 227, 3151-3161 (2012).

46. Tada, $\mathrm{H}$. et al. Elevated extracellular calcium increases expression of bone morphogenetic protein-2 gene via a calcium channel and ERK pathway in human dental pulp cells. Biochem Biophys. Res Commun. 394, 1093-1097 (2010).

47. Wagner, A. S. et al. Osteogenic differentiation capacity of human mesenchymal stromal cells in response to extracellular calcium with special regard to connexin 43. Ann. Anat. 209, 18-24 (2017).

48. Jung, H., Best, M. \& Akkus, O. Microdamage induced calcium efflux from bone matrix activates intracellular calcium signaling in osteoblasts via Ltype and T-type voltage-gated calcium channels. Bone 76, 88-96 (2015).

49. Cummings, L. J., Snyder, M. A. and Brisack, K. Methods in enzymology. in Protein Chromatography on Hydroxyapatite Columns (eds Burgess, R. R. \& Deutscher, M. P.) Ch. 24, 387-404 (Academic Press, San Diego, CA, 2009).

50. Yang, H., Curinga, G. \& Giachelli, C. M. Elevated extracellular calcium levels induce smooth muscle cell matrix mineralization in vitro. Kidney Int. 66, 2293-2299 (2004).

51. Marcondes, M. C. G., Poling, M., Watry, D. D., Hall, D. \& Fox, H. S. In vivo osteopontin-induced macrophage accumulation is dependent on CD44 expression. Cell. Immunol. 254, 56-62 (2008).

52. David, T. D. \& Masaki, N. Osteopontin expression and function: role in bone remodeling. J. Cell Biochem Suppl. 30,31, 92-102 (1998).

53. Gross, T. S., King, K. A., Rabaia, N. A., Pathare, P. \& Srinvasan, S. Upregulation of Osteopontin by osteocytes deprived of mechanical loading or oxygen. J. Bone Miner. Res 20, 250-256 (2005).

54. Kidd, L. J. et al. Temporal pattern of gene expression and histology of stress fracture healing. Bone 46, 369-378 (2010). 